\title{
Promoción de la equidad y cohesión social en la Universidad de Costa Rica
}

\author{
Promotion of the equity and social cohesion in the University of Costa Rica
}

\author{
Stephanie Washburn-Madrigal ${ }^{1}$ \\ Escuela de Orientación y Educación Especial \\ Instituto de Investigación en Educación \\ Universidad de Costa Rica \\ San José, Costa Rica \\ stephanie.washburn@ucr.ac.cr \\ Viria Ureña-Salazar ${ }^{2}$ \\ Escuela de Orientación y Educación Especial \\ Instituto de Investigación en Educación \\ Universidad de Costa Rica \\ San José, Costa Rica \\ viria.urena@ucr.ac.cr \\ Alejandrina Mata-Segreda ${ }^{3}$ \\ Escuela de Orientación y Educación Especial \\ Universidad de Costa Rica \\ San José, Costa Rica \\ mataalejandrina@gmail.com
}

\section{Recibido: 6 Agosto 2012 Aceptado: 8 Agosto 2013 Corregido: 29 Octubre 2013}

Resumen: En el presente artículo se hace referencia a los resultados obtenidos en la primera fase de trabajo de la Red Alfa III, dentro del Programa Marco Interuniversitario para una Política de Equidad y Cohesión Social en la Educación Superior, en relación con la Universidad de Costa Rica, institución socia. Se presenta el análisis realizado a partir de la información encontrada, relativa a las acciones que como institución de educación superior la Universidad desarrolla para favorecer la equidad y la cohesión social. Se concluye que si bien la institución cuenta con una normativa y otros recursos suficientes y pertinentes para promover la justicia e igualdad entre su propia comunidad desde la docencia, la investigación, la acción social y la vida estudiantil, existen otras condiciones psicosociales que no están siendo atendidas de forma oportuna.

1 Bachiller en Ciencias de la Educación con énfasis en Orientación de la Universidad de Costa Rica. Labora como la Asistente de Investigación por parte de la Universidad de Costa Rica, de la Riaipe3. stephanie.washburn@ucr.ac.cr

2 Licencianda en Ciencias de la Educación con énfasis en Orientación de la Universidad de Costa Rica. Labora como docente de la Escuela de Orientación y Educación Especial, así como investigadora del Instituto de Investigación en Educación. viria.urena@ucr.ac.cr

3 Doctora en Educación de la Universidad Nacional de Educación a Distancia de España. Labora como docente de la Escuela de Orientación y Educación Especial, e investigadora del Instituto de Investigación en Educación. mataalejandrina@gmail.com 
Palabras clave: Educación universitaria, cohesión social, pertinencia, igualdad.

\begin{abstract}
This article refers to the results obtained in the first phase of work of the Red Alfa III as the Inter-university Framework Program for Equity and Social Cohesion Policies in Higher Education, with the University of Costa Rica, as a partner institution.

It includes the analysis of the actions for promoting equity and social cohesion, developed by the University as an institution of higher education. It concludes that although the institution has rules enough resources to promote justice and equality in its own community from teaching, research, social action and student life, other psychosocial conditions are not being fulfilled in an appropriate way.
\end{abstract}

Key words: Higher education, social cohesion, relevance, equality

\title{
Introducción
}

En el año 2010 la Universidad de Costa Rica al igual que otras universidades, fue invitada a participar en la Red Alfa III denominada "Programa Marco Interuniversitario para una Política de Equidad y Cohesión Social en la Educación Superior" (Riaipe3), iniciativa promovida por la Comisión Europea. La Red estaba siendo construida con la participación de universidades europeas y latinoamericanas, con el liderazgo de la Universidad Lusófona de Humanidades y Tecnologías de Portugal. Para el año 2011, fecha de inicio de esta actividad, ya se contaba con la participación de 30 instituciones socias de América Latina y Europa, una de ellas es la Universidad de Costa Rica, mediante el proyecto de investigación "Equidad y cohesión social en la educación universitaria", el cual fue inscrito en el Instituto de Investigación en Educación por la Escuela de Orientación y Educación Especial.

Para el desarrollo del programa, el trabajo se organizó en tres fases, cada una con una duración de un año. La primera referida a la elaboración de diagnósticos para identificar la pertinencia de la educación superior en cuanto a la promoción de la equidad y la cohesión social, la segunda orientada hacia la producción de conocimiento al interior de cada institución participante con el fin de aportar a la tercera fase, información que permita la creación de un marco interuniversitaria para la promoción de la equidad y la cohesión social.

Al cabo de este primer año se contó con el diagnóstico requerido de la Universidad de Costa Rica, de ahí que el presente artículo constituye el resumen del informe técnico elaborado. Se esboza, en primera instancia, una síntesis del referente teórico que orientó el trabajo, en vista de que fue preciso definir y hacer operativos conceptos claves incluidos en el proyecto general, tales como equidad, cohesión social y pertinencia universitaria, a los que se agregan otros aspectos teóricos que se consideró que venían a enriquecer el análisis de la información. Se incluye además el marco metodológico que permitió organizar la actividad desde una perspectiva investigativa. En un apartado posterior, se presenta el análisis de la información recolectada, para luego exponer las conclusiones que fueron retomadas en la planificación del trabajo en la segunda fase del Programa. 


\section{Referente teórico}

De acuerdo con los objetivos del proyecto "Programa Marco Interuniversitario para una Política de Equidad y Cohesión Social en la Educación Superior" (Riaipe3), los cuales se retomaron como parte del proyecto de investigación mencionado y que se incluyen en el apartado metodológico, fue necesario asumir una posición teórica que abarcara los temas de equidad, cohesión social y pertinencia universitaria. Por lo tanto el marco conceptual del proyecto incluye como tema abarcador, el enfoque de Desarrollo Humano Sostenible que instrumentaliza el Programa Estado de la Nación ${ }^{4}$ y que permite hacer referencia a los conceptos que se deben retomar.

De esta manera el Desarrollo Humano Sostenible se define como "[...] un proceso continuo e integral, que reúne componentes y dimensiones del desarrollo de las sociedades y de las personas, en los que resulta central la generación de capacidades y oportunidades de, por y para la gente, con las que la equidad se acreciente para las actuales y futuras generaciones" (Programa Estado de la Nación en Desarrollo Humano Sostenible, 1994). Entender el desarrollo humano desde esta perspectiva ubica a las personas en el centro de este proceso, lo cual implica necesariamente que todas y todos tienen igual acceso a las oportunidades, de ahí que el concepto de equidad es fundamental para concebir el desarrollo de las personas y de la sociedad en general. La igualdad en el acceso a las oportunidades para el desarrollo de las capacidades y potencialidades de las personas y es lo que favorece el logro del desarrollo humano sostenible. De esta manera la educación se convierte en el eje para favorecer la calidad de vida de la población, pues se parte de que el capital educativo, entendido como la síntesis del acervo de valores, conocimientos, habilidades y destrezas incorporadas por las personas y grupos en el proceso educativo; es lo que sustenta el desarrollo de una sociedad.

Al definir el Relator de los Derechos Humanos del Instituto Interamericano de Derechos Humanos, que la equidad juega un papel decisivo en la eliminación de la injusticia al acabar o evitar el incremento de la desigualdad (Thompson, 2000), surgió la necesidad de incluir en el análisis el tema de la justicia, entendida por este mismo autor como igualdad. En concordancia con la teoría de la reproducción social o cultural basada en las ideas de Bourdieu (citado por Benadusi, 2001), la igualdad en educación es producto del disfrute de posibilidades abiertas a los beneficios que ofrecen oportunidades educativas de calidad eliminándose las barreras sociales y culturales del sistema educativo. La desigualdad está definida por una diferencia, disparidad o brecha que determina una ventaja o desventaja para algunos en cuanto a los recursos que cuenta la persona como salud, reconocimiento social, prestigio, autoridad, poder

4 El Programa Estado de la Nación (PEN), es un programa de investigación y formación sobre desarrollo humano sostenible que brinda información relevante para la formulación de políticas públicas y opinión crítica de la ciudadanía sobre temas estratégicos, tanto en Costa Rica como en Centroamérica.

El propósito principal es dotar a la sociedad de instrumentos de fácil acceso para conocer su evolución, desarrollar instancias de rendición de cuentas, fortalecer mecanismos de participación, negociación y contribuir a la formación de consensos nacionales, ejercicios imprescindibles en una sociedad democrática.

Entre los estudios que ofrece el PEN está el Informe Estado de la Nación que constituye un sistema de seguimiento y evaluación anual de Costa Rica en desarrollo humano sostenible en aspectos sociales, económ icos, ambientales y políticos principalmente. Hasta el momento el PEN ha publicado dieciocho Informes Estado de la Nación. 
e influencia, en fin, todas aquellas condiciones de las que carecen las personas que viven en pobreza. Esta perspectiva se encuentra íntimamente relacionada con el enfoque de Desarrollo Humano Sostenible pues apela a la creación de oportunidades de desarrollo social y cultural, la facilitación del acceso a estas, la creación de entornos equitativos y el abastecimiento de bienes y servicios para todos y todas, entre otras características. En la corriente del relativismo cultural se inscriben sobre todo los temas transversales, en especial el de género pues parece hacer evidente la interpretación social que se hace acerca del rol de hombres y mujeres en la sociedad y sus posibilidades de desarrollo.

Con este marco conceptual referido a la igualdad se procedió al análisis del tema de la equidad, la cual se entiende desde Hutmaker, Cochran y Bottani (2001) como las medidas compensatorias a favor de los grupos sociales en condición de vulnerabilidad por carecer de capital social, cultural y económico. La equidad es entonces, producto de decisiones políticas que toman en cuenta las diversas posibilidades, ventajas, desventajas y oportunidades reales del estudiantado con el fin que se dé una justa atribución/adquisición de recursos. De la anterior definición de equidad se destacan dos elementos importantes, el primero relacionado con la voluntad política de las autoridades educativas y el segundo relacionado con la persona capaz de aprovechar lo que tiene a su alrededor y con derecho al otorgamiento de ciertas condiciones del contexto. A cerca de lo anterior es importante mencionar que Gewirtz (2004) llama la atención respecto al hecho de que en educación es imposible determinar si una política es equitativa o no, si un sistema educativo es equitativo o no, a menos que se supere una posición abstracta para su análisis y más bien se tome como base una interpretación del contexto y las formas en que dichas políticas son ejecutadas. Es decir, no existen mediciones únicas ni aplicables a todas las condiciones de desigualdad en procura de la equidad, estas dimenciones más bien son producto del análisis particular de la situación, de sus componentes y condiciones estructurales, de las necesidades y visiones del grupo que requiere de este tipo de políticas y de las oportunidades que realmente están en capacidad de acceder.

Por otra parte, el tema de la cohesión social aparece como prioridad de trabajo entre la Unión Europea y América Latina en el año 2004 en la Cumbre Euro - Latinoamericana y para lo cual se definió de la siguiente manera:

La promoción de la cohesión social es esencial para luchar contra la pobreza y la desigualdad. Es también indisociable de la consolidación de la democracia, de una economía eficaz y de un empleo digno para todos. La dificultad consiste en combinar crecimiento económico y empleo, equidad y solidaridad. Este objetivo exige la adopción de estrategias integradas y que se adapten a la realidad concreta de cada país y subregión para conseguir así una interacción óptima de las políticas. Ello supone una gobernanza capaz de interesar al conjunto de los actores y de lograr consenso. (Comisión Europea citado por Martín, 2008, p. 9).

Al igual que con la equidad, las decisiones políticas para la cohesión social son importantes y requieren de un enfoque multidisciplinar, integrado y plural, capaz de adaptarse a la realidad social del contexto, en la misma línea en que lo plantea Gewirtz (2004), y encontrar 
coherencia entre objetivos, plazos, instrumentos y recursos disponibles para alcanzar la cohesión social. Es necesario concretar políticas públicas capaces de articular estrategias de lucha contra la pobreza y la desigualdad, favorecedoras de la inclusión social y del ejercicio de los derechos de la ciudadanía. Se trasciende lo meramente socioeconómico y se centra en una concepción social basada en la solidaridad y la pertenencia mediante el pleno ejercicio de los derechos de ciudadanía (Martín, 2008).

En relación con el término pertinencia, cuando se refiere al contexto educativo remite a la educación "que está en condiciones de aportar a la transformación y desarrollo de las comunidades locales y nacionales, preparar para la inserción en el mundo del trabajo en la medida en que se articula con el sector productivo y aportar a la construcción de un mundo más justo, más equitativo y más comprometido con el ambiente." (Colombia aprende, La red del conocimiento., s.f., 3. Párr.) De esta manera de acuerdo con la UNESCO, la pertinencia de la educación superior tiene que ver con el lugar que ésta ocupa en la sociedad, es decir, su misión en materia de educación, de investigación y de servicios. Por su parte Tunnerman (1999) afirma que la pertinencia de la Educación superior se expresa tal vez mejor a través de la variedad de servicios académicos que presta a la sociedad. A partir de lo anterior la pertinencia se constituye en uno de los indicadores que permiten referirse a la calidad de la educación, de sus respuestas adecuadas y oportunas a los problemas, demandas, necesidades y expectativas de la sociedad, por medio de la formación de profesionales, la investigación y las acciones de extensión, en las diferentes dimensiones de una sociedad, (económica, cultural, política, científica y tecnológica) y que indiscutiblemente inciden en el desarrollo de una nación.

Respecto al concepto de género fue utilizado primeramente en el campo de la antropología en el año 1955, esto para describir los comportamientos socialmente asignados a hombres y mujeres. Pero fue hasta la década de los años 70 que las feministas anglosajonas impulsaron este concepto para hacer énfasis en que las desigualdades existentes entre hombres y mujeres son socialmente construidas y no biológicas (Pérez, 2000). Este mismo autor señala que es en años posteriores cuando el género como término empieza a ser utilizado por varias disciplinas debido a que resultaba útil el hecho de cómo la diferencia biológica se convierte en desigualdad económica, social y hasta política. En este sentido, la adopción del género como categoría de análisis ha significado la ruptura epistemológica más importante de las últimas décadas en las ciencias sociales, pues ha implicado el reconocimiento de una desigualdad social que había sido hasta entonces subsumida en la dimensión económica, tanto por la teoría de las clases como por la de la estratificación social (De Barbieri, 1992). Es así como se vislumbra el inicio de los diferentes esfuerzos (de cada nación y de organismos internacionales) para la existencia de una igualdad de género. La Organización Mundial de la Salud (2011) define el género como:

[...] los conceptos sociales de las funciones, comportamientos, actividades y atributos que cada sociedad considera apropiados para los hombres y las mujeres. Las diferentes funciones y comportamientos pueden generar desigualdades de género, es decir, diferencias entre los hombres y las mujeres que favorecen sistemáticamente a uno de los dos grupos (OMS. s.f., 1. Párr.) 
Al considerarse que "el género es un elemento constitutivo de las relaciones sociales basadas en las diferencias que distinguen los sexos y el género es una forma primaria de las relaciones significantes de poder [...]" (Joan W. Scott citado en Rodríguez, 2000, p. xi), se puede concluir que el género responde a normas socialmente establecidas que determinan las formas de comportamiento y hasta de desarrollo tanto de hombres, como de mujeres. En simples palabras, el género es una construcción social, en donde se remarcan las diferencias entre hombres y mujeres. La existencia de marcadas diferencias entre hombres y mujeres por su género hace que se promueva entonces la desigualdad social, individual, económica y cultural, entre otras. Al existir la desigualdad, existen grandes esfuerzos a nivel mundial en pro de la igualdad de género entre hombres y mujeres. Es decir, sin desigualad no se buscaría la igualdad. Para promover un mejor desarrollo social es preciso promover la igualdad de género, la igualdad de oportunidades, la equidad, es decir, que hombres y mujeres disfruten de los mismos derechos, ya sea de carácter político, social e individual.

En resumen, la consideración de los anteriores temas dentro del enfoque de desarrollo humano sostenible (igualdad, equidad, cohesión social, pertinencia y género) constituyó la perspectiva que facilitó analizar los datos obtenidos en este estudio- diagnóstico, que permite a su vez hacer referencia al papel que ha tiene la Universidad de Costa Rica, como institución de educación superior en cuanto a la promoción de la equidad y la cohesión social.

\section{Aspectos Metodológicos}

$\mathrm{Al}$ ser este un diagnóstico, se buscaba obtener un panorama más preciso de la situación universitaria y derivar elementos de juicio para una futura propuesta de resolución de lo que amerite atención (Rojas Soriano, 1991), se establecieron los siguientes objetivos:

1. Identificar las condiciones en las que la Universidad de Costa Rica atiende las necesidades de su comunidad educativa y su proyección a otras comunidades.

2. Analizar la pertinencia de las diferentes acciones que promueven la equidad y la cohesión social entre las personas que integran la comunidad educativa de la Universidad de Costa Rica.

El método aplicado se sustentó en los principios de complementariedad expuestos por Ortí (1994), que permiten un acercamiento a la realidad social, en primera instancia desde una perspectiva fáctica (acercamiento cuantitativo), en segunda instancia desde la perspectiva de los discursos aplicando ambos paradigmas, para cerrar con la identificación del sentido, consciente o no, de la dinámica universitaria sobre el tema en estudio, a partir de un acercamiento cualitativo.

Mediante la debida adaptación de lo propuesto por Villasante (1994), la perspectiva cualitativa se concretó mediante la aplicación de metodologías participativas en las que quien investiga no es la única persona que pregunta, sino que esta persona es interpelada por las realidades representadas en las personas que integran los grupos significantes para el abordaje de los problemas de investigación planteados. No se trata de la aplicación exclusiva 
del sentido común ni de la cotidianidad sin más, ni del relativismo del "todo se vale" que expone este autor, sino del intento de sistematizar o reelaborar el objeto de estudio a partir de la rigurosidad que exige el método científico basado en la objetividad.

La perspectiva cuantitativa se concretó mediante los métodos de síntesis bibliográfica, síntesis de estadísticas vitales y muestreo selectivo para la aplicación de técnicas de encuesta, entrevista y análisis de contenido (Rojas, 1991). Para el análisis de la información bibliográfica y estadística se utilizó la técnica de codificación tomando como unidad de contenido el tema y para el análisis de la información recolectada mediante el muestreo selectivo se utilizó la estadística descriptiva (Barrantes, 1999).

\section{Procedimiento para la recolección de la información}

Al ser este diseño de carácter estratégico fue necesario elaborar un instrumento metodológico que posibilitara el desarrollo de las actividades investigativas con miras al cumplimiento de los objetivos del estudio, haciendo uso de las técnicas de recolección y análisis de la información más convenientes para la resolución del problema de investigación. Por lo anterior se elaboró una lista de evidencias que fueron agrupadas en dimensiones, cuyas respuestas se constituyeron en datos para su posterior análisis. Cada evidencia se completaba a partir de la aplicación de las técnicas de recolección de información cualitativas y cuantitativas anteriormente expuestas. La resolución de cada evidencia sugería el paso a seguir en esta línea estratégica.

\section{Categorías de Análisis}

Como se indicó anteriormente la lista de evidencias se integraron en dimensiones, que se constituyen en las categorías de análisis y que se detallan a continuación:

I. $\quad$ Dimensión de política, marco legal y programas, que incluye:

a. Marco legal de la Universidad de Costa Rica.

b. Reformas importantes en la Universidad de Costa Rica.

c. Políticas específicas y compensatorias existentes con relación a becas e igualdad de oportunidades.

d. Programas de apoyo a grupos vulnerables para su ingreso, permanencia en la Universidad y su inserción el mercado laboral.

e. Declaraciones explícitas sobre lo anterior.

f. Artículos de leyes, reglamentos o convenios que defienden el derecho a la educación de grupos vulnerables.

II. Dimensión institucional:
a. Titularidad.
b. Misión.
c. Estructura y sistema de gobierno. 
d. Ordenamiento interno.

e. Articulación horizontal y vertical.

f. Análisis FODA sobre necesidades de grupos vulnerables.

g. Estrategias de permanencia e inserción en el mercado laboral de los grupos vulnerables.

h. Sistemas de evaluación institucional que incluya indicadores de atención a grupos vulnerables.

i. Histórico del presupuesto anual de atención de grupos vulnerables.

j. Existencia de una plan de igualdad de oportunidades.

k. Dimensión internacional de la institución.

III. Dimensión alumnado y representatividad, que agrupa:

a. Perfil estudiantil.

b. Acceso.

c. Permanencia.

d. Número de solicitantes.

e. Ingreso.

f. Egreso.

g. Estudios sobre grupos vulnerables.

h. Etnia.

i. Representación de grupos vulnerables en los órganos de gobierno.

IV. Dimensión profesorado, personal de investigación y cargos relevantes:
a. Tipos de régimen del profesorado.
b. Distribución por categorías y cargos relevantes en la administración universitaria.
c. Estímulo a la investigación.

V. Dimensión de planes de estudio - docencia, conformada por:
a. Oferta de planes de estudio.
b. Desarrollo académico.
c. Currículum y transversalidad curricular.
d. Adecuación a la demanda social.
e. Perspectiva de género en la docencia, currículum, metodología.

VI. Dimensión de investigación, que incluye:
a. Concepción sobre el conocimiento.
b. Acceso a publicaciones y eventos científicos.
c. Perfil del personal investigador.
d. Líneas de investigación. 
VII. Dimensión de transferencia y extensión:

a. Políticas y programas de extensión para la atención de grupos vulnerables.

b. Relación con los sectores sociales.

c. Actividades de visibilidad de los grupos vulnerables.

d. Perspectiva de género en la transferencia.

VIII. Dimensión de evaluación.

\section{Fuentes de Información}

Las fuentes consultadas y las técnicas de recolección de la información utilizadas fueron las siguientes:

- Solicitud oficial de información a las jefaturas universitarias responsables de los diferentes procesos de gestión que pueden incidir en la equidad y cohesión social en la universidad: Oficina de Registro e Información, Oficina de Becas y Atención Socioeconómica, Oficina de Bienestar y Salud, Oficina de Orientación, Oficina de Recursos Humanos, Oficina de Planificación Universitaria y Consejo Universitario.

- Discusión de informes de investigación con la Unidad de Estudios de la Vicerrectoría de Vida Estudiantil, a partir de los estudios realizados hasta la fecha y entregados oficialmente al equipo investigador.

- Entrevista grupal a la Comisión de Desarrollo Personal del Estudiantado de la Oficina de Orientación.

- Conversaciones electrónicas con la Oficina de Asuntos Internacionales y con el Centro de Orientación Vocacional, Ocupacional de la Oficina de Orientación y con la Oficina de Planificación Universitaria.

- Síntesis estadística de la información brindada por la Oficina de Registro e Información, la Oficina de Becas y Atención Socioeconómica y Oficina de Planificación Universitaria.

- Análisis de contenido de leyes, estatutos y reglamentos referidos a los temas propios de esta investigación, del Plan Estratégico 2008-2012, de los informes anuales de la Rectoría de la Universidad de Costa Rica, entre otros documentos propiamente universitarios.

- Entrevistas a informantes clave de las siguientes instancias universitarias: Centro de Evaluación Académica, Oficina de Orientación.

- Análisis documental de las normas institucionales, políticas, resoluciones, publicaciones académicas e informes de la Rectoría.

En vista del enfoque estratégico del trabajo se aclara que el equipo de investigación estableció la indagación sobre grandes focos de atención y que fue el aporte de las personas 
participantes en esta actividad de investigación, el que determinó los énfasis y los caminos a seguir para la recolección de la información que resultara pertinente al presente trabajo. Igualmente la valoración final sobre la pertinencia universitaria es producto de una construcción participativa incluyendo al equipo de investigación y a las personas que integran la comunidad universitaria y que aportaron sus conocimientos, experiencia y juicios de valor conforme al interés de la investigación.

\section{Resultados}

A continuación se presentan los resultados por dimensión analizada, de manera resumida.

\section{Dimensión de política, marco legal y programas}

El tema político y normativo cobra importancia cuando de equidad y cohesión social se habla en vista de la necesidad de consolidar contextos que favorezcan el desarrollo de acciones específicas que promuevan dichas condiciones. De ahí la pertinencia de iniciar la recolección y análisis de resultado a partir de esta dimensión. La Universidad de Costa Rica fue fundada el 26 de agosto de 1940 mediante la Ley de la República número 0362 e inició formalmente sus funciones el 7 de marzo de 1941 (Asamblea Legislativa, 1940). Mediante esta ley se concibe a la Universidad como una institución de docencia y cultura superior que promueve el estudio de las ciencias, las letras y las bellas artes, con la misión de difundir este conocimiento y preparar para el ejercicio de las profesiones. El Estatuto Orgánico de la institución establece que el Congreso Universitario es el órgano decisorio que incluye la mayor representación de la comunidad universitaria, espacio en el que a lo largo de su historia, la Universidad ha introducido las transformaciones más importantes que inciden en las condiciones de equidad y cohesión social a lo interno y en su proyección hacia la sociedad en general. Como ejemplo de lo anterior se tiene que en 1946 se sentaron las bases para la creación de la Facultad de Humanidades para cumplir con la histórica misión de incluir en la formación profesional una visión integral de la persona. En 1973 el Congreso situó a la institución en la realidad de la sociedad que la alimenta y a la que sirve. Se emanaron los principios que inspiraron el actual Estatuto Orgánico como la elevación al rango de Vicerrectoría el tema de la vida estudiantil y la concepción articulada de la docencia, la investigación y la acción social.

En las actuales políticas universitarias, emitidas por el Consejo Universitario, es posible identificar una vocación institucional hacia la promoción de la igualdad de oportunidades y de favorecimiento a la permanencia estudiantil. Ejemplo de lo anterior son las siguientes:

3.2.3. Fortalecerá estrategias de financiación del Sistema de Becas y Beneficios complementarios y la oferta de los servicios, que garanticen la satisfacción de las necesidades de toda la población estudiantil universitaria de escasos recursos económicos, para que pueda culminar su meta académica en igualdad de condiciones. 
5.1.7. Desarrollará estrategias para garantizar oportunidades y accesibilidad de todos sus servicios a los grupos con necesidades especiales en todas las instancias universitarias.

5.1.8. Establecerá los mecanismos para proteger y promover el derecho a la maternidad y paternidad responsables, en especial a la población estudiantil beneficiaria del Régimen de becas y otros beneficios. (Universidad de Costa Rica, 2008, p. 7-9)

Las políticas universitarias sobre cobertura y equidad, y sobre bienestar en la vida universitaria, atienden tanto a poblaciones vulnerables como al resto de la comunidad educativa, debido a que desde el punto de vista universitario la vulnerabilidad es una condición a la que está expuesta toda persona de manera temporal o permanente.

En la Universidad de Costa Rica se desarrollan varias acciones descritas como servicios o programas institucionales en beneficio de grupos vulnerables para la promoción de su acceso, permanencia, graduación e inserción en el mercado laboral. Las instancias responsables de su ejecución son:

- Vicerrectoría de Vida Estudiantil y su dependencia la Oficina de Orientación.

- Centro de Orientación Vocacional-Ocupacional.

- Oficina de Registro en Información.

- Oficina de Bienestar y Salud.

- Oficina de Becas y Atención Socioeconómica.

Entre las normas que dan fundamento a las actuaciones de las instancias mencionadas se destacan:

- Reglamento de Régimen Académico Estudiantil.

- Reglamento de Admisión a la Universidad de Costa Rica por Prueba de Aptitud Académica.

- Reglamento de adjudicación de becas y otros beneficios estudiantiles.

- Reglamento de beneficios de residencias para la población estudiantil de la Universidad de Costa Rica.

- Reglamento de las Casas Infantiles Universitarias.

- Reglamento de Régimen Académico Estudiantil.

Cada uno de estos reglamentos pueden hallarse en el enlace: (http://www.cu.ucr.ac.cr).

Cabe señalar que la Constitución Política de la República de Costa Rica de 1949, concibe a la educación superior como parte del sistema educativo nacional y la Ley Fundamental de 
Educación de 1957, en su artículo 22, garantiza servicios que fortalecen el desarrollo estudiantil, principio normativo que sustenta la existencia de las anteriores instancias y reglamentos. Otras leyes de carácter nacional que inciden en los reglamentos universitarios son la Ley 7600 de Igualdad de Oportunidades para las personas con discapacidad, y a la vez la Convención de Derechos de las personas con discapacidad, acogida en Costa Rica mediante la Ley 8661. En cuanto al tema de la equidad de género, se halla la Ley de Promoción de la Igualdad social de la mujer. Cada una de estas leyes puede encontrarse en el enlace http://www.asamblea.go.cr/ Legislacion/default.aspx

Los datos anteriores muestran que en Universidad de Costa Rica existen dos planos diferenciados entre lo que es la estrategia institucional para promocionar la equidad y la cohesión social mediante la búsqueda constante de igualdad de oportunidades y la cultura de la institución sobre este mismo tema. Sobre lo primero puede asegurarse que la institución a lo interno ha emitido normativa suficiente para dar atención a la población con mayor vulnerabilidad, relacionada con las necesidades educativas especiales, la género, situación socioeconómicas y la salud y la desarrollo integral del estudiantado. La concepción humanística que caracteriza a la Universidad y que se concreta en el principio de que cada estudiante es el centro de atención de su quehacer, sin imponer limitaciones por condiciones relacionadas con etnia, estatus social, género, procedencia geográfica u otras condiciones particulares, es la que sustenta estas normas institucionales. A lo largo del tiempo se han generado reformas universitarias de las cuales cabe destacar la consolidación de una estructura para la gestión curricular basada en la formación humanística y la consideración de la vida estudiantil al mismo nivel de importancia del quehacer académico. Esta visión ha marcado las decisiones universitarias relacionadas con la atención de las necesidades de su comunidad educativa arriba mencionadas. La práctica universitaria se centra en aportar iniciativas abarcadoras e inclusivas de manera que no se considera necesario el desarrollo de programas específicos para diferentes grupos (étnicos, socioculturales), aunque actualmente se encuentra en construcción un proyecto especial para estudiantes de comunidades indígenas, referido más bien a la comprensión de la incidencia cultural en los procesos de aprendizaje de los y las jóvenes de estas comunidades. Los servicios de apoyo a la salud física y mental están abiertos a toda la comunidad estudiantil mediante la modalidad de programas y la atención a condiciones de riesgo psicosocial se atiende o se refiere sin que medie una caracterización estadística que limite o circunscriba los recursos universitarios a dichas problemáticas. La Universidad se ha comprometido en la actualidad con la sociedad costarricense en cuanto a la ampliación de la cobertura, garantizar la permanencia estudiantil, fortalecer la calidad académica y brindar mayores posibilidades de acceso a la educación universitaria, mediante la regionalización ${ }^{5}$ por lo que respecta al acceso y equidad la institución se puede considerar como pertinente.

Sin embargo, en lo que se refiere al segundo plano mencionado, es decir, a la cultura institucional, es difícil llegar a una valoración conclusiva sobre el grado de implementación real de la igualdad de oportunidades en todas las áreas de acción universitaria. Si bien hay acciones que buscan la transformación de la cultura institucional mediante acciones afirmativas concretas, no ha sido posible medir con certeza este grado de transformación. De acuerdo con la percepción

5 Organización institucional en sedes y recintos universitarios a lo largo del país. 
del grupo de profesionales que brindan orientación a la comunidad universitaria, aún prevalece la atención por medio de programas a aquellas situaciones y poblaciones que se encuentran respaldadas por una regulación nacional sin que se tomen en consideración otros fenómenos que requieren de acciones afirmativas para prevenir la exclusión, como por ejemplo la identidad de género, la violencia doméstica, los grupos de personas inmigrantes, el abuso sexual, la prevención de embarazos no deseados, las subculturas juveniles, el decaimiento de la organización estudiantil, la relación entre área de formación profesional y la discriminación por género, entre otras.

\section{Dimensión institucional}

Una organización universitaria puede reflejar su nivel de pertinencia, en alguna medida, a partir de su estructura organizativa. Debe considerarse la necesidad de que su organigrama, con mayor o menor grado de jerarquización, facilite la existencia de múltiples vías para la gestión entre instancias de igual o diverso nivel jerárquico, más aún, garantizar el mayor grado de participación de quienes se encuentran inmersos en su dinámica; solo de esa manera es posible dar respuesta expedita a las necesidades conocidas o emergentes de quienes integran los diversos grupos poblacionales de esta comunidad (estudiantado, personal docente y administrativo). De allí la importancia de analizar las formas en las que se establecen estas interrelaciones en la institución.

De acuerdo a con su Estatuto Orgánico, el propósito de la Universidad de Costa Rica es "contribuir con las transformaciones que la sociedad necesita para el logro del bien común, mediante una política dirigida a la consecución de una justicia social, de equidad, del desarrollo integral, de la libertad plena y de la total independencia de nuestro pueblo" (Universidad de Costa Rica, 1974, p. 1). Como institución autónoma, está constituida por una comunidad conformada por docentes, estudiantes y personal administrativo, dedicado a la docencia, la investigación y la acción social, el estudio, la meditación, la creación artística y la difusión del conocimiento. La estructura organizativa de la Institución integra las diversas áreas de su quehacer académico, a saber la docencia, la investigación y la acción social, en procura de la participación democrática en la toma de decisiones, mediante la representación de la comunidad universitaria en los órganos de gobierno y de administración. De esta manera la estructura orgánica de la Universidad se integra de la siguiente manera:

- La Asamblea Universitaria es la instancia de más alta jerarquía y participación de la Universidad, en la cual reside la máxima autoridad de la institución.

- El Consejo Universitario es el órgano al que le corresponde la definición de las políticas generales y la fiscalización de la gestión, integrado por representantes de los diversos sectores académicos, el sector administrativo y estudiantil, electos por votación directa.

- La Rectoría es la autoridad ejecutiva que igualmente es elegida democráticamente por un período de 4 años. Es responsable de la orientación, dirección y evaluación de las actividades de la institución, responsabilidad que ejecuta con el apoyo de las diferentes Vicerrectorías, a saber: Docencia, Investigación, Vida Estudiantil, Acción Social y Administración, además recibe el apoyo de la Oficina Jurídica, la de Asuntos Internacionales y Cooperación Externa, la de Planificación Universitaria, la Ejecutora del Plan de Inversiones y el Centro de Informática. 
De acuerdo con el artículo 8 del Estatuto Orgánico (Universidad de Costa Rica, 1974, p. 2), "la Universidad está constituida por facultades, escuelas, departamentos, secciones, sedes regionales, estaciones experimentales, centros e institutos de investigación y servicios administrativos y técnicos". Las facultades están organizadas en seis áreas: Artes y Letras, Ciencias Básicas, Ciencias Sociales, Salud, Ciencias Agroalimentarias y el área de Ingeniería.

Para hacer efectiva la estructura universitaria anteriormente expuesta la Universidad de Costa Rica tiene una serie de articulaciones de carácter vertical, las cuales son fácilmente reconocibles, pero además se dan vínculos que facilitan una articulación más efectiva entre instancias de diferente jerarquía sin que necesariamente se tenga que pasar por la estructura jerárquica. Por ejemplo, cada Unidad Académica tiene la potestad y los mecanismos necesarios para dirigirse directamente a cualquiera de las Vicerrectorías o a alguna de sus oficinas coadyuvantes en busca de procurar servicios de apoyo a su propio estudiantado, personal docente y administrativo, sin necesidad de agotar las instancias superiores.

Tomando como base el documento que describe el FODA institucional, se observa la propuesta de factores claves de éxito que orientan la gestión universitaria y la mención permanente al tema de la pertinencia tanto hacia dentro como hacia fuera de la Universidad. A continuación se presentan algunos elementos de este análisis FODA que recogen elementos relacionados con el tema de la equidad y la cohesión social.

Cuadro 1. Ejes y factores claves de éxito definidos a partir del FODA institucional, Universidad de Costa Rica.

\begin{tabular}{|c|c|}
\hline Ejes & Factores claves de éxito \\
\hline Eje docencia & $\begin{array}{l}\text { - Innovación pedagógica } \\
\text { - Desarrollo académico del personal docente }\end{array}$ \\
\hline $\begin{array}{l}\text { Eje desarrollo } \\
\text { académico }\end{array}$ & $\begin{array}{l}\text { - Planificación académica } \\
\text { - Articulación dinámica de docencia, investigación y } \\
\text { acción social. }\end{array}$ \\
\hline Eje de investigación & $\begin{array}{l}\text { - Patrimonio cultural y natural del país. } \\
\text { - Evaluación e investigación. }\end{array}$ \\
\hline $\begin{array}{l}\text { Eje de vida } \\
\text { estudiantil }\end{array}$ & $\begin{array}{l}\text { - Sistema de ingreso de estudiantes a la institución. } \\
\text { - Población graduada. } \\
\text { - Movilidad estudiantil }\end{array}$ \\
\hline Eje de gestión & $\begin{array}{l}\text { - Sistemas de información } \\
\text { - Planificación y evaluación }\end{array}$ \\
\hline Eje de acción social & $\begin{array}{l}\text { Compromiso de las instancias universitarias con el } \\
\text { fortalecimiento y la innovación de programas y proyectos } \\
\text { de acción social. }\end{array}$ \\
\hline
\end{tabular}

Fuente: Plan de Desarrollo Institucional 2008-2012, Universidad de Costa Rica. 
Los ejes utilizados para organizar el plan estratégico institucional reflejan la estructura organizativa de la institución, un eje para cada área académica (docencia, investigación y acción social), un eje propio de la vida estudiantil y uno referido al tema de la calidad universitaria entendido como desarrollo académico. Los factores clave seleccionados como muestra incluyen la responsabilidad institucional no solo con su desarrollo interno y sus actores, sino que también la responsabilidad social que debe asumir como institución universitaria. El eje de desarrollo académico es favorecido en gran medida por los programas que dirige la Oficina de Asuntos Internacionales y Cooperación Externa, destacándose dos de ellos, el de movilidad del conocimiento y el de movilidad de recursos humanos. El pilar de la estrategia de internacionalización de la Universidad de Costa Rica se basa en la movilidad académica y la formación del recurso humano a nivel de posgrado en instituciones de gran prestigio en el exterior.

Interesa destacar de manera específica la actuación institucional dirigida a la población estudiantil en lo que respecta a su acceso, permanencia y graduación. Una de las instancias claves que brindan servicios directos e indirectos al estudiantado (es decir, por medio de las unidades académicas), además de desarrollar programas para toda la comunidad estudiantil en general, es la Oficina de Orientación de la Vicerrectoría de Vida Estudiantil. En esta oficina se encuentra el Centro de Orientación Vocacional - Ocupacional que brinda servicios a la población estudiantil referidos a la atención individual y grupal por motivos vocacionales-ocupacionales. El acceso a estos servicios puede hacerse por iniciativa personal o por referencia de un funcionario administrativo o docente. Asimismo se brindan talleres de preparación para la búsqueda de empleo, a la vez que la Universidad cuenta con un servicio de intermediación de empleo estudiantil que consiste en una plataforma tecnológica por la web, que permite la vinculación directa entre representantes de instancias empleadoras, la población estudiantil y dependencias universitarias para la oferta de puestos de trabajo y la búsqueda de empleo. Se dirige a estudiantes que ya se han graduado o en vísperas de su graduación de todas las carreras de la Universidad. En la actualidad, 4479 se ha registrado en el sistema y 1536 mantienen público su currículum vitae, la cantidad de empresas tanto de sector público como privado que se han inscrito en el sistema es de 225.

La Oficina de Planificación Universitaria realiza el monitoreo y evaluación de las acciones establecidas en su Plan de Desarrollo Institucional mediante un sistema de indicadores de eficiencia y eficacia, incluyéndose entre otros, indicadores relacionados con la gestión de acciones de equidad y cohesión social. 


\section{Cuadro 2. Indicadores de eficiencia y eficacia para la evaluación de las acciones universitarias que promueven equidad y cohesión social, establecidas en el Plan de Desarrollo Institucional 2008-2012, Universidad de Costa Rica.}

\begin{tabular}{llll}
\hline Nombre & Descripción & $\begin{array}{l}\text { Unidad de } \\
\text { medida }\end{array}$ & $\begin{array}{l}\text { Fórmula de } \\
\text { cálculo }\end{array}$ \\
\hline Becas asignadas & $\begin{array}{l}\text { Número de becas otorgadas a } \\
\text { estudiantes y a funcionarios } \\
\text { universitarios. }\end{array}$ & Número de becas & $\begin{array}{l}\text { Conteo de las becas } \\
\text { asignadas. }\end{array}$ \\
$\begin{array}{l}\text { Estudiantes } \\
\text { atendidos }\end{array}$ & $\begin{array}{l}\text { Número de estudiantes } \\
\text { que son atendidos en los } \\
\text { diferentes servicios que } \\
\text { presta la Universidad. }\end{array}$ & $\begin{array}{l}\text { Número de } \\
\text { estudiantes. }\end{array}$ & $\begin{array}{l}\text { Conteo de los } \\
\text { estudiantes } \\
\text { atendidos. }\end{array}$ \\
$\begin{array}{l}\text { Estudiantes } \\
\text { atendidos } \\
\text { según tipo de } \\
\text { discapacidad }\end{array}$ & $\begin{array}{l}\text { Número de estudiantes con } \\
\text { algún tipo de discapacidad } \\
\text { que son atendidos en la } \\
\text { Institución }\end{array}$ & $\begin{array}{l}\text { Número de } \\
\text { estudiantes }\end{array}$ & $\begin{array}{l}\text { Conteo de los } \\
\text { estudiantes } \\
\text { atendidos }\end{array}$ \\
& $\begin{array}{l}\text { Son los estudiantes } \\
\text { beneficiados con algún tipo } \\
\text { de subsidio (becas, ayuda } \\
\text { económica, servicios de: } \\
\text { alimentación, médicos, } \\
\text { de biblioteca y préstamos } \\
\text { económicos, entre otros) }\end{array}$ & $\begin{array}{l}\text { Número de } \\
\text { estudiantes }\end{array}$ & $\begin{array}{l}\text { Conteo de } \\
\text { estudiantes becados }\end{array}$ \\
$\begin{array}{l}\text { Estudiantes } \\
\text { becados }\end{array}$ & & & \\
& & & \\
\hline
\end{tabular}

Fuente: Plan de Desarrollo Institucional 2008-2012, Universidad de Costa Rica.

Para concretar las acciones anteriores y otras más relacionadas con la promoción de la equidad y la cohesión social, la Universidad de Costa Rica invirtió en el año 2012, por ejemplo, el 5\% de su presupuesto en el programa de becas. En los servicios de orientación y salud el 0,97\%. En una institución como la universitaria en la que es usual que más del $80 \%$ de su presupuesto sea invertido en recursos humanos, la asignación de estos porcentajes en programas de apoyo directo al estudiantado para promover su permanencia puede ser considerada significativa y consistente con las políticas a las que anteriormente se hizo mención.

Es mediante acciones como las anteriores que la Universidad se propone ofrecer igualdad de oportunidades, a saber: brindando apoyo en el plano socioeconómico al estudiantado, favoreciendo su desarrollo vocacional, promoviendo su salud y reconociendo sus necesidades especiales, por lo que la institución no cuenta con un plan específico y aislado para lo anterior, sino que es parte de su misión, visión y filosofía. Debe reconocerse sin embargo que en virtud del dinamismo determinado por el desarrollo social y cultural de esta y todas las sociedades del mundo, cada día se reconocen otras condiciones en las poblaciones universitarias que 
requieren de una atención particular y que aún no se han institucionalizado de forma específica. Ejemplo de lo anterior es la condición de las poblaciones inmigrantes al país y el surgimiento de subculturas juveniles, entre otros fenómenos que todavía no se conocen a profundidad y que reciben apoyo institucional en virtud de otras características más generales ya consideradas y no por lo particular que ocasiona visiones externas hacia estos grupos que condicionan su grado de vulnerabilidad.

A manera de resumen, se puede indicar que la Universidad de Costa Rica cuenta con una institucionalidad que le permite atender el mandato que tanto la Constitución Política de Costa Rica como su Estatuto Orgánico le ha impuesto. Si bien aún conserva una estructura orgánica de carácter jerárquico y en gran medida tradicional, ha logrado establecer mecanismos de vinculación en diversos planos orgánicos para la consecución de sus fines. Es importante que la institución reflexione alrededor de las posibilidades que esta estructura le seguirá ofreciendo en el futuro cercano ante la transformación del conocimiento y de las condiciones socio culturales que están cambiando vertiginosamente en la sociedad costarricense. Este parece ser un tema pertinente de discusión en el seno de las instancias de mayor participación con que cuenta la institución.

\section{Dimensión alumnado y representatividad}

En esencia, la Universidad se debe a sus estudiantes. Fomenta la criticidad, desarrolla conocimiento y favorece el desarrollo de las capacidades para el empleo de sus graduados y graduadas, puesto que así lo requieren los sujetos de su actuación académica. Es por esto que este estudio hizo referencia de manera específica a la condición del alumnado y su representatividad social.

El estudiantado que conforma la Universidad proviene de instituciones educativas de diversas modalidades. En el año 2009, de acuerdo con el cuadro 3, fueron admitidos y admitidas 7046 estudiantes provenientes de las siguientes instituciones:

Cuadro 3. Procedencia de la población estudiantil de primer ingreso por tipo de institución, Universidad de Costa Rica, 2009.

\begin{tabular}{lcc}
\hline \multicolumn{1}{c}{ Institución de procedencia } & Número de estudiantes & Porcentaje \\
\hline Colegios públicos & 4580 & 65.00 \\
\hline Educación abierta & 179 & 2.54 \\
Colegios privados con subvención estatal & 293 & 4.16 \\
Colegio privados & 1951 & 27.69 \\
Exterior & 43 & 0.61 \\
TOTAL & 7046 & 100 \\
\hline
\end{tabular}

Fuente: VI Informe Anual de Labores de Rectoría 2009-2010. 
Se observa que el 67,54 \% de la población estudiantil admitida en el año 2009 corresponde a instituciones públicas, incluyendo la educación abierta, mientras que el 31,85\% proviene de instituciones privadas.

De acuerdo con el III Informe del Estado de la Educación (2010, p. 184), en Costa Rica la tasa de matrícula en la educación terciaria es del $25,3 \%$ y se estima que un poco más de la mitad de estas personas es de sexo femenino. De igual manera se estima que el $18 \%$ cursa sus estudios en la universidad pública y se afirma que el incremento en la matrícula de la Universidad de Costa Rica en los últimos años se concreta en las sedes regionales.

En cuanto al acceso, el principal mecanismo para el ingreso a la institución es la Prueba de Aptitud Académica (PAA) por el cual se admite el mayor número de estudiantes y el que retoma la población proveniente de las instituciones de secundaria. Lo referente a este proceso de admisión se encuentra estipulado en el "Reglamento del proceso de admisión mediante la Prueba de Aptitud Académica" (Gaceta Universitaria 01-2003, 2003). En este reglamento se indica que la PAA tiene como principios la igualdad de oportunidades a todas aquellas personas que deseen realizar estudios universitarios; el principio de rectitud, de transparencia y de justicia en el proceso de admisión, el principio de excelencia académica y el principio de óptima utilización de los recursos de la Universidad, esto en beneficio de la sociedad costarricense. Es decir, estos principios buscan equidad, justicia y la garantía de excelencia en el proceso de admisión de las personas a la institución.

Algunas carreras de la Universidad en particular, plantean la realización de pruebas específicas además de la PAA. Es decir, para que una persona ingrese a la Universidad de Costa Rica, debe contar con los siguientes requisitos indispensables, mencionados en el artículo 3 del reglamento:

a) Efectuar la PAA en el lugar y fecha que la Universidad de Costa Rica defina para tal efecto.

b) Aprobar otras pruebas de aptitud específicas indicadas por las Unidades Académicas, cuando estas existan.

c) Obtener el puntaje mínimo en la nota de admisión que establece el Consejo Universitario.

d) Haber obtenido el Diploma de Bachiller en Educación Media o su equivalente, reconocido y equiparado por el Consejo Superior de Educación cuando el estudiante proceda de colegio del exterior.

e) Concursar por el ingreso a una carrera y quedar admitido en la Universidad.

Otro mecanismo de ingreso a la Universidad de Costa Rica es mediante el "Convenio de articulación y cooperación de la Educación Superior Estatal de Costa Rica" que posibilita la continuación de los estudios superiores, es la modalidad universitaria del estudiantado de Colegios Universitarios y la Escuela Centroamericana de Ganadería, en aquellas carreras con las que la Universidad ha establecido un convenio de articulación. 
El comportamiento histórico de admisión a la Universidad de Costa Rica se presenta en el siguiente cuadro.

\section{Cuadro 4. Estudiantes por etapa del proceso de admisión, Universidad de Costa Rica, 2000-2011.}

\begin{tabular}{ccccccc}
\hline Período & $\begin{array}{c}\text { Personas } \\
\text { Inscritas }\end{array}$ & $\begin{array}{c}\text { Realizaron } \\
\text { la PAA }\end{array}$ & $\begin{array}{c}\text { Personas } \\
\text { Elegibles }\end{array}$ & $\begin{array}{c}\text { Personas } \\
\text { Concursantes }\end{array}$ & $\begin{array}{c}\text { Personas } \\
\text { Admitidos }\end{array}$ & $\begin{array}{c}\text { Personas } \\
\text { Matriculadas }\end{array}$ \\
\hline $\mathbf{1 9 9 9 - 2 0 0 0}$ & 21111 & 19475 & 13268 & -- & 6067 & 5124 \\
$\mathbf{2 0 0 0 - 2 0 0 1}$ & 22880 & 21038 & 14482 & 7779 & 5492 & 4683 \\
$\mathbf{2 0 0 1 - 2 0 0 2}$ & 26070 & 23860 & 16300 & 7963 & 5729 & 4870 \\
$\mathbf{2 0 0 2 - 2 0 0 3}$ & 27654 & 25460 & 14363 & 8274 & 5882 & 5001 \\
$\mathbf{2 0 0 3 - 2 0 0 4}$ & 29669 & 27460 & 15718 & 9951 & 6005 & 5470 \\
$\mathbf{2 0 0 4 - 2 0 0 5}$ & 31780 & 28694 & 16287 & 10083 & 6391 & 5527 \\
$\mathbf{2 0 0 5 - 2 0 0 6}$ & 32311 & 28743 & 15964 & 9137 & 6424 & 5471 \\
$\mathbf{2 0 0 6 - 2 0 0 7}$ & 33250 & 28648 & 24788 & 13249 & 7275 & 6283 \\
$\mathbf{2 0 0 7 - 2 0 0 8}$ & 34087 & 29573 & 18479 & 9692 & 7221 & 5963 \\
$\mathbf{2 0 0 8 - 2 0 0 9}$ & 33678 & 29074 & 18144 & 9192 & 7046 & 5817 \\
\hline $\mathbf{2 0 0 9}-2010$ & 35172 & 31047 & 16603 & 8437 & 7115 & 5852 \\
\hline $\mathbf{2 0 1 0 - 2 0 1 1}$ & 37546 & 32071 & 18344 & 10472 & 7458 & 6209 \\
\hline
\end{tabular}

Fuente: Información brindada por la Oficina de Registro e Información de la Universidad de Costa Rica, mediante oficio ORI-2198-2011.

Como se puede observar, el número de personas inscritas en la PAA cada año VA en aumento gracias a la ampliación de oportunidades que el sistema educativo ofrece para acceder a la educación media, sin embargo hay una reducción significativa entre este número de personas y aquellas que finalmente concretan su matrícula. En medio de este camino se observa que alrededor de la mitad del estudiando resulta elegible, probablemente la otra mitad no resultó serlo por falencias en su formación media. Solo alrededor de la sexta parte es admitida y un poco menos de estos concretan su matrícula. Se hace evidente que la Universidad de Costa Rica es una de las instituciones de educación superior estatal a la que mayor número de estudiantes solicitan admisión año tras año, pero que no está en capacidad de atender la demanda total aunque el estudiantado haya ganado la Prueba de Aptitud Académica. La PAA es un instrumento sometido permanentemente a revisión y mejoramiento con el fin de garantizar equidad y posibilidades de éxito en la formación universitaria, el procedimiento se encuentra debidamente normado y existen las instancias responsables de velar por su correcta aplicación. 
Como se ha indicado anteriormente, la promoción de la permanencia estudiantil en la Universidad de Costa Rica no debe ser comprendida únicamente desde el punto de vista del establecimiento de programas de ayuda a grupos vulnerables, sino que se incluyen las acciones que brindan apoyo de tipo académico y personal social para toda la población. Se han dirigido esfuerzos para la creación y fortalecimiento de programas para el bienestar estudiantil. Algunos de estos esfuerzos se traducen en servicios que brinda la Universidad para la atención de grupos vulnerables, pero también a toda la población estudiantil. Vale la pena puntualizar el trabajo que realizan las tres oficinas coadyuvantes de la Vicerrectoría de Vida Estudiantil:

- Oficina de Becas y Atención Socioeconómica: define como su misión el favorecer la equidad de oportunidades para realizar estudios universitarios mediante un sistema solidario de becas y atención socioeconómica, que permita el desarrollo académico de la población estudiantil de escasos recursos económicos, así como otros beneficios que estimulen la formación integral y la obtención de un grado académico.

- Oficina de Bienestar y Salud: encargada de la promoción y de los servicios de salud integral, dirigida a toda la población universitaria.

- Oficina de Orientación: es la responsable de brindar servicios y desarrollar proyectos que acompañan al y a la estudiante, durante su proceso de ingreso, permanencia y graduación. Está conformada por profesionales de distintas disciplinas, los cuales atienden las necesidades estudiantiles. Esta Oficina está conformada por los Centros de Asesoría Estudiantil (CASE); Centro de Orientación Vocacional (COVO); Centro de Asesoría a Estudiantes con Discapacidad (CASED) y la Casita Infantil Universitaria (CIU).

Un tema de interés a destacar es la existencia de programas de reconocimiento de aquellos y aquellas estudiantes con excelencia académica, siendo este un factor motivador. En el Reglamento de Régimen Académico Estudiantil del año 2001 (Gaceta Universitaria 03-2001, 2001, p.11) se estipula lo siguiente relacionado al rendimiento académico y la excelencia académica:

ARTÍCULO 32. La Universidad utiliza el promedio ponderado anual para determinar el rendimiento académico del estudiante. La Oficina de Registro e Información es la responsable de efectuar el cálculo del promedio ponderado del estudiante, en las primeras semanas de cada año, y de notificarlo oportunamente al alumno y a las entidades universitarias que lo requieran. Dicho cálculo tiene vigencia para todos los aspectos de la vida universitaria durante el año.

ARTÍCULO 33. La excelencia académica se reconocerá mediante diversos mecanismos que se encuentran en la normativa institucional vigente.

Se reitera por lo tanto que la promoción de la permanencia en la Universidad de Costa Rica, no se reduce únicamente al fortalecimiento de los servicios brindados a población en situaciones de vulnerabilidad a nivel socioeconómico, sino que también los esfuerzos institucionales se dirigen hacia la atención de aquellos y aquellas estudiantes con bajo 
rendimiento académico. Es así como la visión integrada de la permanencia en la Universidad, abarca desde los aspectos académicos, económicos, sociales y hasta de parentalidad.

Como parte de los esfuerzos realizados por la Universidad para el ajuste del estudiantado al ambiente universitario, se realizan acciones de recibimiento de las y los estudiantes de nuevo ingreso. Así por ejemplo durante el año 2011, la Vicerrectoría de Vida Estudiantil organizó las "Jornadas de Inducción" en las que participan los y las estudiantes de primer ingreso. Se favorece el reconocimiento de de los servicios de mayor interés para esta población y otros como la biblioteca, el taller de desarrollo de la carrera profesional, reglamentación estudiantil universitaria, información sobre el movimiento estudiantil, ciclo de salud integral, toma de carné estudiantil y tour por el campus universitario.

Es entonces a partir de lo anterior, que se evidencia como en la Universidad de Costa Rica, el ingreso a la Universidad se entiende no solo como un proceso de admisión, sino como un proceso de transición, un proceso de integración a la vida y comunidad universitaria, con el fin de que las y los estudiantes de nuevo ingreso logren incorporarse, y afrontar con éxito la transición de la educación secundaria a la educación superior, así como lograr la comprensión de la nueva etapa del desarrollo que se inicia.

El siguiente cuadro presenta información relacionada con la graduación estudiantil.

\section{Cuadro 5. Personas graduadas de pregrado y grado, por área y grado académico obtenido. Universidad de Costa Rica, 2009.}

\begin{tabular}{lcccccccc}
\hline & \multicolumn{2}{c}{ Total } & \multicolumn{2}{c}{ Diplomado } & \multicolumn{2}{c}{ Bachillerato } & \multicolumn{2}{c}{ Licenciatura } \\
& abs. & $\%$ & $a b s$. & $\%$ & $a b s$. & $\%$ & $a b s$. & $\%$ \\
\cline { 2 - 9 } Universidad de Costa Rica (Total) & 4399 & 100,0 & 190 & 4,32 & 2495 & 56,72 & 1714 & 38,96 \\
Sede Rodrigo Facio & 3468 & 78,84 & 166 & 4,79 & 1761 & 50,78 & 1541 & 44,43 \\
Artes y Letras & 235 & 5,34 & & & 181 & 77,02 & 54 & 22,98 \\
Ciencias Básicas & 139 & 3,16 & & & 123 & 88,49 & 16 & 11,51 \\
Ciencias Sociales & 1890 & 42,96 & 145 & 7,67 & 967 & 51,16 & 778 & 41,16 \\
Salud & 593 & 13,48 & 19 & 3,20 & 193 & 32,55 & 381 & 64,25 \\
Ciencias Agroalimentarias & 108 & 2,46 & & & 71 & 65,74 & 37 & 34,26 \\
Ingenieríy y Arquitectura & 503 & 11,43 & 2 & 0,40 & 226 & 44,39 & 275 & 54,67 \\
\hline Sedes Regionales & 931 & 21,16 & 24 & 2,58 & 734 & 78,84 & 173 & 18,58 \\
\hline
\end{tabular}

Fuente: VI Informe Anual de Labores de Rectoría 2009-2010.

Del total de 4399 personas graduadas de pregrado y grado en el año 2009, el mayor número lo hace en la Sede Rodrigo Facio, que es el recinto principal de la Universidad. La mayoría proviene del área de Ciencias Sociales y el menor número en Ciencias Agroalimentarias. Es 
importante destacar que el $21 \%$ de las personas graduadas durante este año corresponde a la población de las Sedes Regionales, las cuales se encuentran en diferentes lugares del país con el fin de hacer la Universidad más accesible a las personas que por su ubicación geográfica se les dificulta acceder a la sede central.

En cuanto a los estudios de posgrado, en el año 2009 se graduaron un total de 778 estudiantes. La distribución por grado académico y sexo se presenta en el siguiente cuadro:

\section{Cuadro 6. Personas Graduadas por posgrado, Sistema de Estudios de Posgrado. Universidad de Costa Rica, 2009.}

\begin{tabular}{lccccccc}
\hline & \multicolumn{2}{c}{ Total } & \multicolumn{2}{c}{ Femenino } & \multicolumn{2}{c}{ Masculino } \\
& abs. & $\%$ & $\boldsymbol{a b s}$. & $\%$ & $\boldsymbol{a b s}$. & $\%$ \\
\cline { 2 - 8 } Sistema de Estudios de Posgrado & 778 & 100,0 & 415 & 53,34 & 363 & 46,66 \\
Doctorado & 18 & 2,31 & 7 & 38,89 & 11 & 61,11 \\
Maestrías Académicas & 97 & 12,47 & 62 & 63,92 & 35 & 36,08 \\
Maestrías Profesionales & 378 & 48,59 & 195 & 51,59 & 183 & 48,41 \\
Especialidad & 285 & 36,63 & 151 & 52,98 & 134 & 47,08 \\
\hline
\end{tabular}

Fuente: VI Informe Anual de Labores de Rectoría 2009-2010.

El mayor número de títulos otorgados corresponden a maestrías profesionales, más de la mitad de las personas graduadas son mujeres, sin embargo el porcentaje de hombres que obtienen el doctorado es mucho mayor que el de mujeres, mientras que más mujeres se gradúan en las maestrías. Es importante destacar este sesgo de género que refleja la mayor oportunidad que tienen los hombres de dedicar más tiempo a los estudios de posgrado que las mujeres.

La Universidad de Costa Rica ha venido desarrollando estudios relacionados con condiciones de vulnerabilidad que se generan en el contexto en el que se desenvuelven sus estudiantes y aquellas poblaciones estudiantiles que tienen la expectativa de ingresar a ella. Es por esto se han analizado temas como la equidad en el acceso a la Universidad, que analiza la procedencia geográfica, educativa y cultural de las poblaciones universitarias, la equidad en el proceso de admisión que analiza una vez más los mecanismos establecidos para la selección estudiantil y otras opciones de admisión por carrera. El tema de procedencia étnica no ha sido considerado dentro de las estadísticas universitarias, de hecho en el país esta perspectiva apenas se ha considerado en el Censo Nacional recientemente aplicado en el año 2011, en el que se le pregunta a la población cómo se califique a si misma de acuerdo con la etnia que corresponda. De igual manera, ni en la Universidad de Costa Rica ni en los órganos de gobierno nacional se hace una diferenciación de la participación por consideraciones de vulnerabilidad a excepción de lo establecido en la Ley de Igualdad Real de la Mujer, de Costa 
Rica, que se exige la consideración de cuotas en los órganos de gobierno. Es por esta razón que se han iniciado estudios sobre las poblaciones estudiantiles de las comunidades indígenas que permitan el reconocimiento de las condiciones culturales que determinan sus procesos de aprendizaje.

La información recolectada mediante estos estudios muestra un sesgo importante hacia las poblaciones más favorecidas del país, pues si bien la proporción de estudiantes que estudia en colegios públicos y colegios privados en el país es de 9 a 1 respectivamente, 4 de cada 10 estudiantes que ingresan a la Universidad de Costa Rica provienen de colegios privados. Ya se había mencionado el hecho de que finalmente ingresa a la Universidad una pequeña proporción del estudiantado que aspira a hacerlo por lo que la institución plantea el fortalecimiento y mejoramiento de los procedimientos de admisión. Este proceso es complejo, ya que busca en buena medida introducir elementos que se constituyan en un igualador social en vista de los niveles de desigualdad social que presenta el país. Este es uno de los retos que en la actualidad se ha planteado la institución.

En resumen, la presente dimensión refleja las condiciones en las que se desarrollan la población estudiantil de la Universidad de Costa Rica, algunas más favorables que otras, pero siempre con el marcado compromiso institucional por la promoción de la equidad y la cohesión social entre sus estudiantes.

\section{Dimensión profesorado, personal de investigación y cargos relevantes}

Al estar establecido en sus normas que la Universidad de Costa Rica es una comunidad integrada por estudiantes, personal docente y administrativo, el tema considerado en la presente dimensión es relevante igualmente para el análisis de la equidad y la cohesión social.

El Reglamento de Régimen Académico y Servicio Docente de la Universidad (Gaceta Oficial 76-82, 2008), clasifica en categorías académicas al profesorado de la siguiente manera: instructor, profesor adjunto, profesor asociado, profesor catedrático. Estas categorías se asignan de acuerdo con un sistema de méritos que incluyen los títulos académicos, el tiempo en el ejercicio de la docencia, además de otros requisitos asociados a la calificación que le otorgan sus estudiantes como docente, las publicaciones que haya hecho, sus funciones en investigación, acción social, entre otros. Este profesorado es el que tiene su puesto en propiedad, pero además existe la categoría de interinazgo para aquellas y aquellos docentes que no han logrado obtener una plaza en propiedad o que se encuentran sustituyendo a colegas que ocupan otros puestos administrativos o se encuentran becados en el exterior.

Un tema importante de destacar es la condición de interinazgo del profesorado por razones obvias de estabilidad laboral y de ascenso en régimen académico. Es decir, esta condición hace que al regreso de la persona propietaria de la plaza docente, produzca que quien ha sido su sustituto se pueda quedar sin empleo. Además, para acceder a otras categorías en Régimen Académico es necesario tener una plaza en propiedad lo que constituye una limitante adicional. El gráfico siguiente describe la proporción de personal docente interino en relación con el que se encuentra en propiedad. 


\section{Gráfico 1. Relación entre el profesorado en propiedad y el profesorado en condición de interinazgo, 2004-2011.}

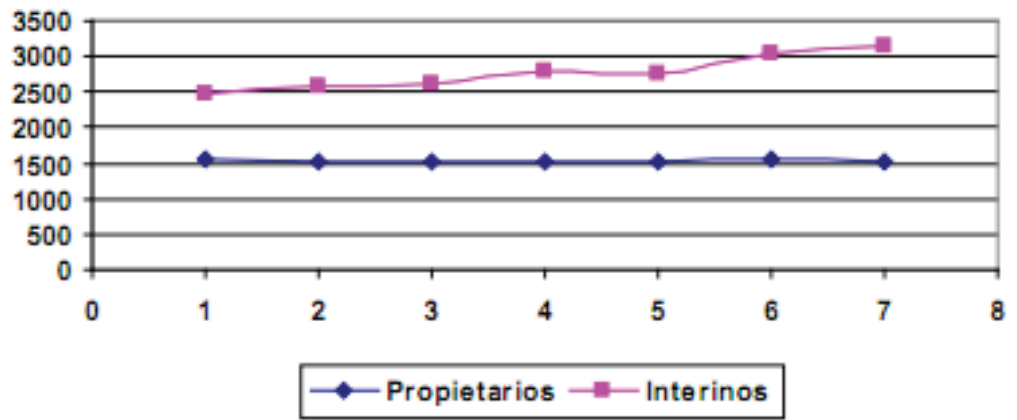

Fuente: VII Informe Anual de Labores de Rectoría 2010-2011.

Puede observarse que es mayor el grupo de docentes que se encuentra en condición de interinazgo que el grupo de docentes que se encuentra en propiedad. Igualmente se observa que el número de personas propietarias de su plaza se mantiene estable a lo largo del tiempo, no así el de personas interinas que va aumentando año a año aunque sea levemente.

El cuadro siguiente refleja otro ángulo merecedor de análisis sobre esta situación.

Cuadro 7. Profesorado de la Universidad de Costa Rica de acuerdo con su categoría en Régimen Académico, su grado académico y su sexo, 2010.

\begin{tabular}{|c|c|c|c|c|c|c|c|c|c|c|c|c|c|c|}
\hline \multirow{2}{*}{$\begin{array}{l}\text { Grado en } \\
\text { Régimen } \\
\text { Académico }\end{array}$} & \multicolumn{2}{|c|}{ Bachillerato } & \multicolumn{2}{|c|}{ Licenciatura } & \multicolumn{2}{|c|}{ Maestría } & \multicolumn{2}{|c|}{ Doctorado } & \multicolumn{2}{|c|}{ Otro } & \multicolumn{2}{|c|}{ NS } & \multicolumn{2}{|c|}{ Total } \\
\hline & M & $\mathrm{H}$ & M & $\mathrm{H}$ & M & $\mathrm{H}$ & M & $\mathrm{H}$ & M & $\mathrm{H}$ & M & $\mathrm{H}$ & M & $\mathrm{H}$ \\
\hline $\begin{array}{l}\text { Interino/ } \\
\text { Interina }\end{array}$ & 39 & 45 & 116 & 101 & 94 & 53 & 16 & 28 & 44 & 32 & 10 & 4 & 319 & 263 \\
\hline $\begin{array}{l}\text { Adjunto/ } \\
\text { adjunta }\end{array}$ & 0 & 0 & 3 & 6 & 5 & 3 & 2 & 2 & 0 & 0 & 0 & 0 & 10 & 11 \\
\hline $\begin{array}{l}\text { Instructor/ } \\
\text { instructora }\end{array}$ & 6 & 4 & 43 & 49 & 41 & 27 & 8 & 7 & 0 & 0 & 0 & 0 & 98 & 87 \\
\hline $\begin{array}{l}\text { Asociado/ } \\
\text { Asociada }\end{array}$ & 1 & 0 & 8 & 13 & 54 & 34 & 18 & 18 & 0 & 0 & 0 & 0 & 81 & 65 \\
\hline $\begin{array}{l}\text { Catedrático/ } \\
\text { catedrática }\end{array}$ & 0 & 0 & 1 & 4 & 22 & 19 & 20 & 38 & 0 & 0 & 0 & 0 & 43 & 61 \\
\hline Total & 46 & 49 & 171 & 173 & 216 & 136 & 64 & 93 & 0 & 0 & 10 & 4 & 551 & 487 \\
\hline
\end{tabular}

Fuente: Información brindada por la Oficina de Recursos Humanos de la Universidad de Costa Rica, mediante oficio ORH-3320-2011. 
Las estadísticas del año 2010 sobre este personal muestra que hay más profesoras interinas y profesores interinos que profesores en propiedad como se indicó en el gráfico 1, la mayoría son de sexo femenino y a la categoría académica de doctorado pertenecen más hombres que mujeres. En cuanto al personal en propiedad, nótese que hay más hombres con la categoría de catedrático que mujeres con la categoría de catedrática.

Este sesgo por género no se observa entre quienes han venido ocupando los cargos docentes administrativos relevantes en la institución, a excepción del puesto de Rector o Rectora (en su historia la institución solo ha tenido una mujer ocupando este cargo superior) y la Vicerrectoría de Administración, que en la última década siempre ha sido ocupada por hombres. A continuación se presenta un cuadro que resume lo anterior entre los años 2001 a 2010.

Cuadro 8. Cargos relevantes en la gestión universitaria por sexo, 2001- 2010. Universidad de Costa Rica

\begin{tabular}{|c|c|c|}
\hline Cargo & Mujeres & Hombres \\
\hline Rectoría & 1 & 1 \\
\hline Presidencia Consejo Universitario & 6 & 6 \\
\hline Vicerrectoría de Administración & 0 & 4 \\
\hline Vicerrectoría de Acción Social & 2 & 0 \\
\hline Vicerrectoría de Docencia & 1 & 2 \\
\hline Vicerrectoría de Investigación & 2 & 1 \\
\hline Vicerrectoría de Vida Estudiantil & 1 & 1 \\
\hline Oficina Ejecutora del Plan de Inversiones & 0 & 1 \\
\hline Oficina Jurídica & 0 & 1 \\
\hline Oficina Asuntos Internacionales y Cooperación Externa & 1 & 1 \\
\hline Oficina Planificación Universitaria & 2 & 0 \\
\hline Centro de Informática & 0 & 2 \\
\hline TOTAL & 16 & 20 \\
\hline
\end{tabular}

Fuente: Elaboración propia del equipo investigador.

En relación con la investigación, la Vicerrectoría de Investigación no lleva un registro detallado del número de docentes que realizan investigación pues la información que aporta más bien está referida a la participación del profesorado en proyectos de investigación por año, sin tomar en cuenta la vigencia de estos proyectos. En la siguiente tabla se incluye información que puede dar una idea de la proporción entre investigadoras e investigadores por año. 


\section{Cuadro 9. Número de personas investigadoras por año,}

distribuidas por sexo, 2000-2010.

\begin{tabular}{cccc}
\hline Año & Hombres & Mujeres & Total \\
\hline 2000 & 453 & 352 & 805 \\
2001 & 468 & 358 & 826 \\
2002 & 439 & 376 & 815 \\
2003 & 458 & 380 & 838 \\
2004 & 469 & 387 & 856 \\
2005 & 483 & 412 & 895 \\
2006 & 497 & 433 & 930 \\
\hline 2007 & 536 & 474 & 1010 \\
2008 & 570 & 493 & 1063 \\
\hline 2009 & 586 & 522 & 1108 \\
\hline 2010 & 607 & 558 & 1165 \\
\hline
\end{tabular}

Fuente: VII Informe Anual de Labores de Rectoría 2010-2011.

De acuerdo con la información anterior, más hombres que mujeres se dedican a la investigación por año a pesar que hay más profesoras que profesores laborando en la Universidad.

En resumen, la situación del profesorado universitario muestra elementos sesgados a favor de uno y a favor de otros. Así, hay más mujeres docentes que hombres docentes en la Universidad, pero son más las interinas que los interinos. Si bien son más las profesoras en propiedad, son los hombres los que han alcanzado los títulos más altos y los que han alcanzado las categorías más altas en régimen académico. Esta situación igualmente debe ser analizada por la comunidad universitaria y cuestionarse si se estará cumpliendo con lo que establecen las normas nacionales referentes a la igualdad de oportunidades entre géneros.

\section{Dimensión de planes de estudio - docencia}

El plan de estudios es la herramienta que hace realidad, en la formación del estudiantado, los principios que la Universidad se ha propuesto seguir. De ahí la importancia de analizar lo referente a este tema en la Universidad de Costa Rica con miras a promover la equidad y la cohesión social.

La Universidad de Costa Rica brinda más de doscientas carreras a nivel de grado (bachillerato y licenciatura) que se encuentran organizadas en seis áreas del conocimiento: 
Ciencias Sociales, Agroalimentarias, Ingenierías, Salud, Artes y Letras, Ciencias Básicas. Todas las carreras tienen en común la formación humanística que se organiza en un sistema que incluye los Cursos Integrados de Humanidades, los Cursos de Repertorio y los Seminarios de Realidad Nacional.

Cuadro 10. Distribución histórica de planes de estudio por grado acad
\begin{tabular}{lcccc}
$\mathbf{2 0 0 7}-\mathbf{2 0 1 0}$. \\
$\begin{array}{l}\text { Ocferta } \\
\text { académica }\end{array}$ & $\mathbf{2 0 0 7}$ & $\mathbf{2 0 0 8}$ & $\mathbf{2 0 0 9}$ & $\mathbf{2 0 1 0}$ \\
\hline Bachillerato & 126 & 126 & 133 & 136 \\
\hline Licenciatura & 89 & 90 & 91 & 91 \\
\hline Diplomado & 3 & 6 & 8 & 8 \\
Profesorado & 13 & 16 & 14 & 17 \\
\hline
\end{tabular}

Fuente: VII Informe Anual de Labores de Rectoría 2010-2011.

La oferta académica no solo se ha incrementado en los últimos años con algunas carreras nuevas de tipo interdisciplinario, sino que además el número de grupos de cursos lo ha hecho como producto del incremento de matrícula en los últimos años. El siguiente gráfico muestra este crecimiento.

\section{Gráfico 2. Oferta académica de cursos regulares, tutorías y suficiencias, 2005-2009.}

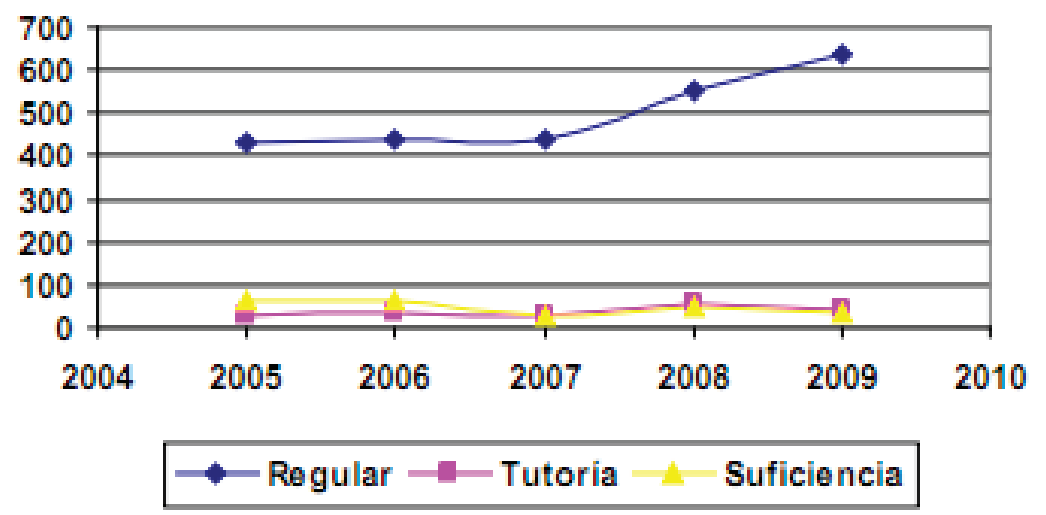

Fuente: VII Informe Anual de Labores de Rectoría 2010-2011.

Puede observarse que a partir del año 2007 se da un crecimiento importante en el número de cursos que se imparten, esto asociado al incremento del número de estudiantes admitidos a partir de ese momento. 
Para la creación de planes de estudio, la Universidad brinda apoyo a las Unidades Académicas mediante el Centro de Evaluación Académica (CEA), que además cumple con la función de emitir criterios técnicos que utiliza la Vicerrectoría de Docencia para aprobar las nuevas propuestas curriculares. Del análisis documental y de información recolectada mediante entrevistas, se identificaron áreas temáticas que pueden ser consideradas como ejes transversales para la formación de profesionales en todas las áreas de conocimiento que atiende la institución, a saber: flexibilidad, formación humanista, compromiso de la Universidad con la sociedad, no atomización, investigación, trabajo interdisciplinario, vinculación teoríapráctica, integración ciencia-tecnología-arte y filosofía y desarrollo sostenible. El tema de la igualdad de oportunidades en razón del género no se esboza explícitamente en los documentos del CEA pues se sobreentiende que el Consejo Universitario ya ha emitido políticas al respecto que deben concretarse en todas las acciones que se realizan en la Universidad. Además se promueve la vinculación directa del estudiantado con el contexto nacional y una visión más integral de la tarea profesional, centrada en el bienestar individual y colectivo.

Si bien estas condiciones para la formación profesional encuentran su asidero en las normas universitarias, en especial en su Estatuto Orgánico y al aprobarse un plan de estudios se ha verificado que la planificación curricular sea reflejo de estas visiones, no se puede asegurar que lo establecido en los planes de estudio se cumple en todos los casos, ni que en caso de cumplimiento, este sea plenamente satisfactorio en relación con los principios universitarios. Se ha manifestado que el CEA no es una "auditoría académica" por lo que el seguimiento a la calidad de la formación está en manos de las mismas Unidades Académicas.

El diseño curricular es considerado por el CEA como una tarea altamente participativa, en la que deben involucrarse todas las personas que construyen el currículo, aportando a la negociación de diversas visiones de mundo en un contexto determinado para que la propuesta tenga posibilidades de adecuarse a la demanda social. Por lo tanto, la primera tarea a realizar es el diseño del marco epistemológico y socio-histórico. A la par de este marco se construye el enfoque pedagógico como elemento que viene a concretar lo anterior de manera que el producto final sea una formación profesional consciente de las necesidades de desarrollo social.

Una prioridad universitaria es el desarrollo académico del personal académico, por lo que han creado diferentes modalidades a las que en común puede acceder el personal docente de todas las carreras, además de las iniciativas particulares que cada Unidad Académica organice. Es por ello que se puede hacer referencia a la Red Institucional de Formación y Evaluación Docente (RIFED) que constituye un espacio de interacción institucional con el fin de promover el desarrollo académico del profesorado universitario (Rifed, s.f.). Se menciona igualmente la Oficina de Asuntos Internacionales y Cooperación Externa (OAICE), encargada de promover el desarrollo académico de la institución a partir de los beneficios y de las posibilidades que ofrece la internacionalización de la educación superior en el mundo (Oficina de Asuntos Internacionales, s.f.)

En el caso del desarrollo profesional del personal académico hay evidencia de una oferta permanente de actualización y opciones de educación de posgrado. Sin embargo datos relacionados con la distribución del profesorado por categoría académica y titulación muestran una tendencia más favorable hacia el desarrollo académico de los profesores aunque hay más profesoras que profesores en la institución como se mostró en la dimensión anterior. 
El análisis realizado sobre esta dimensión temática a partir de los indicadores considerados demuestra el mayor compromiso universitario en lo que respecta a la consistencia entre la orientación filosófica institucional y los mecanismos de creación y ejecución de los planes de estudio. No obstante, a falta de instrumentos de seguimiento, no puede caracterizarse el grado de concreción de lo establecido en los planes de estudio en cada uno de los planes que se ofrecen. Es probable que la adopción de sistemas de acreditación de carreras sea el ingrediente por el que han optado las Unidades Académicas para valorar la calidad de la formación que desarrollan.

\section{Dimensión de investigación}

La generación del conocimiento es una de las funciones primordiales de la Universidad. Sin embargo lo que la hace pertinente es generar el conocimiento que requiere la sociedad para su desarrollo y ponerlo a disposición de quien lo requiera. Esto último favorece la promoción de la cohesión social en la medida que pueda establecerse el diálogo entre la institución universitaria y la ciudadanía.

Para efectos de este trabajo se destacan las siguientes políticas referidas al área de investigación:

1.1.8. Fortalecerá la investigación, el registro, la catalogación, la conservación, la restauración y la exhibición del patrimonio universitario y nacional, tangible e intangible, con una perspectiva de accesibilidad y uso por parte de la comunidad universitaria y nacional.

1.1.10. Impulsará el estudio de los problemas nacionales con un enfoque interdisciplinario.

2.2.6. Fortalecerá la investigación y la acción social en aquellas unidades académicas y unidades administrativas, en las cuales hay poco desarrollo.

2.2.7. Apoyará el uso de nuevas tecnologías, para optimizar los procesos de enseñanzaaprendizaje y fortalecer la investigación y la acción social, así como para agilizar los procesos de admisión, permanencia y graduación.

2.3.2. Impulsará la articulación de actividades de docencia, investigación y acción social, para el desarrollo de las instancias que posee en el territorio nacional.(Consejo Universitario, s.f.)

Se destaca de lo anterior, en primera instancia el mandato de favorecer la vinculación universitaria con las necesidades del país. Se establece además una relación entre las tres grandes áreas académicas universitarias, a saber: la docencia, la investigación y la acción social, lo cual en esta institución es de primera entrada factible en vista de que las investigadoras y los investigadores son el mismo personal docente, lo que puede facilitar dicha integración.

Se ponen a disposición del profesorado y del estudiantado 16 bibliotecas que administran recursos que apoyan las carreras en todas sus sedes y recintos con un horario accesible. 
Entre los servicios más destacados está el préstamo del acervo bibliográfico, el acceso a bases de datos, la formación de usuarios y usuarias de bibliotecas, apoyo con equipo audiovisual, impresiones de diferentes materiales, localización de documentos, biblioteca virtual, en total 34 diferentes tipos de servicios. Para el estudiantado con deficiencia visual ofrece la traducción al Sistema Braille y pone también a su disposición el software JAWS que traduce el texto escrito en comunicación oral. Su infraestructura es accesible físicamente. (Informe de Autoevaluación de la Carrera Bachillerato y Licenciatura en Ciencias de la Educación con énfasis en Orientación, 2011).

Por otra parte, cada Unidad Académica e Instituto o Centro de Investigación define sus líneas de investigación, las cuales deben responder directamente a las políticas universitarias en este campo, aunque la Vicerrectoría de Investigación propone sus propias políticas y directrices así como sus objetivos que orientan el trabajo. Para su logro pone a disposición del personal de investigación los mecanismos necesarios para su ejecución. Esta Vicerrectoría muestra un compromiso explícito con la calidad y la excelencia de esta actividad académica, y con la facilitación de medios para su realización y no necesariamente con áreas temáticas o con otros principios o valores sociales. Se observa nuevamente el respeto a la capacidad autónoma de decisión de cada Unidad Académica, en este caso, para la definición de la orientación que quiera darle a su proyecto investigativo. Lo anterior se hace evidente al analizar los objetivos y directrices políticas de la Vicerrectoría de Investigación.

\section{- Objetivos}

- Promover y facilitar el desarrollo armónico de la investigación en todas las disciplinas sin detrimento de ninguna de ellas; apoyar, preferentemente, las propuestas multidisciplinarias de interés institucional y nacional.

- Proveer los instrumentos que permitan evaluar la labor de investigación de los centros e institutos; procurar además que sean útiles para planificar o modificar racionalmente sus propios lineamientos.

- Directrices políticas

- Asegurar la calidad y promover la excelencia de la investigación.

- Evaluar esfuerzos y estimular a los investigadores e investigadoras.

- Promover los procesos de evaluación de la ciencia, en donde es pertinente evaluar las colectividades y no solo los individuos. (Portal de la Investigación, s.f., 4. Párr )

Un aspecto importante de señalar es la cantidad de proyectos de investigación y otras actividades investigativas que se desarrollan por área del conocimiento. 
Cuadro 11. Histórico de proyectos de investigación por área académica, 2005 - 2010. Universidad de Costa Rica

\begin{tabular}{lcccccccc}
\hline & Agroalimentarias & Básicas & Sociales & $\begin{array}{c}\text { Ing. } \\
\mathbf{y} \\
\text { Arq. }\end{array}$ & $\begin{array}{c}\text { Artes } \\
\mathbf{y} \\
\text { Letras }\end{array}$ & Salud & $\begin{array}{c}\text { Sedes } \\
\text { Regionales }\end{array}$ & $\begin{array}{c}\text { Otras } \\
\text { áreas }\end{array}$ \\
\hline $\mathbf{2 0 0 5}$ & 180 & 298 & 282 & 100 & 107 & 174 & 69 & 32 \\
$\mathbf{2 0 0 6}$ & 200 & 319 & 322 & 99 & 112 & 163 & 69 & 35 \\
$\mathbf{2 0 0 7}$ & 205 & 330 & 319 & 96 & 109 & 160 & 72 & 35 \\
$\mathbf{2 0 0 8}$ & 215 & 330 & 333 & 93 & 103 & 174 & 75 & 38 \\
$\mathbf{2 0 0 9}$ & 212 & 331 & 324 & 110 & 104 & 190 & 79 & 34 \\
\hline $\mathbf{2 0 1 0}$ & 226 & 360 & 331 & 115 & 117 & 208 & 88 & 32 \\
\hline
\end{tabular}

Fuente: VII Informe Anual de Labores de Rectoría 2010-2011.

En el área que más se investiga en la Universidad es la de Ciencias Básicas que constituye el área de mayor tradición en el mundo entero. Le siguen las Ciencias Sociales, y si bien la institución le da un espacio importante a la investigación en esta área, se debe tomar en cuenta que es la que alberga más carreras, más profesorado y más presupuesto, lo que incide en la cantidad de investigación que se realiza.

Tal y como se indicó, el personal docente es el mismo personal investigador. A continuación se presente la relación histórica entre investigadores de ambos sexos.

\section{Gráfico 3. Relación histórica entre el número de investigadores e} investigadoras en la Universidad de Costa Rica, 2005 - 2010.

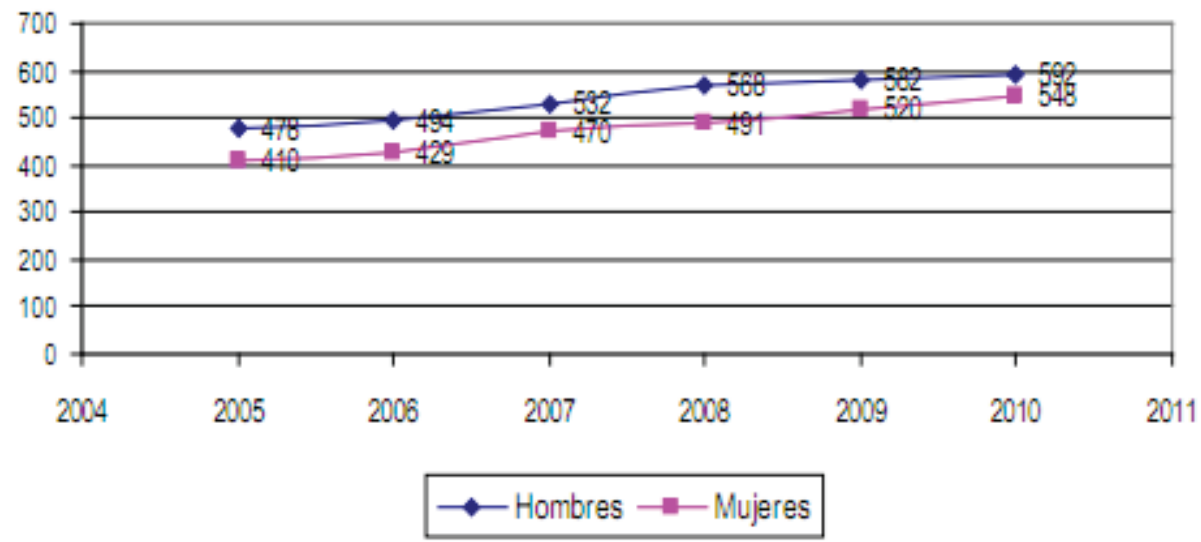

Fuente: VII Informe Anual de Labores de Rectoría 2010-2011. 
Recuérdese que en la Universidad de Costa Rica hay más profesoras que profesores, es decir, habría potencialmente más investigadoras que investigadores. No obstante esta premisa no se cumple, lo que constituye nuevamente una alerta para ser reflexionada por la comunidad universitaria. Esta situación es consistente con el dato de que en la institución hay más hombres con el grado de doctorado que mujeres.

Tanto en su estructura política como de acción, la Universidad de Costa Rica estimula el desarrollo de la investigación a partir de grandes lineamientos más relacionados con principios que con líneas rígidas de investigación. Esta condición evidentemente es una fortaleza institucional pues evita cierto dogmatismo referido a temas y metodologías que harían que el conocimiento producido no dé respuesta pertinente a las necesidades del contexto en que se encuentra inmersa la institución. No obstante es preciso que la institución analice las posibilidades reales que el personal académico tiene de acceder al campo investigativo, sobre todo, el personal femenino.

\section{Dimensión de transferencia y extensión}

En la Universidad de Costa Rica los temas de transferencia y extensión tienen que ver con la acción social, la cual tiene su lugar en la estructura organizativa de la Universidad de Costa Rica, con el rango de Vicerrectoría. Esta dimensión es crucial para la valoración que se haga sobre la pertinencia universitaria, sobre todo en la medida en que promueva la equidad y la cohesión social. Esta acción académica responde en la Universidad de Costa Rica a las siguientes políticas emanadas por el Consejo Universitario:

1.1.2. Promoverá el análisis, la discusión y la participación en la solución de los problemas nacionales, con el fin de plantear propuestas que beneficien a la sociedad costarricense, con énfasis en aquellos sectores más vulnerables y excluidos socialmente

1.1.3. Promoverá los mecanismos necesarios para que la capacidad académica institucional se ponga al servicio de la comunidad, con el propósito de lograr, en conjunto, las transformaciones requeridas para el mejoramiento de la calidad de vida.

1.1.4. Utilizará su producción académica para fortalecer los procesos de innovación relacionados con su quehacer, con el fin de obtener las transformaciones que la sociedad necesita para el logro del bien común, en un marco de equidad y justicia (www.cu.ucr.ac.cr)

Es así como dentro de las políticas universitarias se refleja su voluntad explícita de dar respuestas a las necesidades de desarrollo del país desde la docencia y la investigación, utilizando como vehículo primordial la acción social. Este involucramiento incluye la aplicación del conocimiento académico en distintos campos como la transferencia tecnológica, el estudio de la situación nacional y la propuesta de acciones que beneficien a diferentes poblaciones, el rescate y conservación de la cultura y las expresiones artísticas, entre otras acciones. La visión universitaria hacia el exterior se enmarca en una concepción integral del quehacer humano en sociedad por lo que toda instancia universitaria está en posibilidad de aportar al bienestar y desarrollo de la comunidad nacional. 
Los anteriores principios devienen en criterios útiles para la definición de estrategias para realizar la acción social con miras al cumplimiento de las políticas universitarias en cuanto a su compromiso con el desarrollo y mejoramiento de la sociedad costarricense, donde las personas o grupos menos favorecidos se convierten en una población meta importante de acciones inclusivas. La relación con los sectores sociales se atiende mediante el trabajo inter y transdisciplinario; en contacto con las personas y el ambiente, complementa y enriquece su quehacer por medio de programas institucionales, procesos culturales, educación continua, extensión docente, trabajo comunal universitario y los medios de comunicación.

El Trabajo Comunal Universitario (TCU) es una actividad de servicio a la comunidad que realiza cada estudiante con una duración de 300 horas y es requisito indispensable para obtener el título de Bachillerato. Es de naturaleza interdisciplinaria y cada estudiante centra su acción alrededor de la disciplina en la que se está formando. En el año 2011 el $33 \%$ de los proyecto ofrecidos al estudiantado se ubicaron en el área de Ciencias Sociales y el 14\% en el área de la Salud. Cabe destacar que el 28\% de las opciones de TCU fueron ofrecidos en las Sedes Regionales brindando la oportunidad de que la Universidad refuerce su presencia en las comunidades alejadas del país. Las proporciones más altas se ubican en los proyectos que trabajan con pequeñas y medianas empresas (19\%), comunidades con necesidades para la gestión del riesgo (14\%), niños, niñas y adolescentes (14\%) y personas con VIH, cáncer y enfermedades crónicas (12\%). De acuerdo con el Informe de la Rectora del año 2011, el profesorado que dirige estos proyectos se encuentra en condición de interinazgo lo que preocupa, principalmente, por el reconocimiento de las limitadas posibilidades de vinculación real de los TCU en los distintos quehaceres académicos.

La extensión cultural es otra de las modalidades de acción social. Busca dinamizar los procesos de construcción de la cultura para mejorar la calidad de vida de la población, a partir de la promoción y el fortalecimiento de la gestión cultural, artística y de apoyo a la construcción del patrimonio cultural. Se centra en el desarrollo de proyectos en las comunidades con la participación de docentes, estudiante, investigadores e investigadoras para la promoción del multiculturalismo y el fortalecimiento de la identidad cultural. Como ejemplos importantes se destacan el de promoción y difusión de la cultura afrocaribeña, el fortalecimiento de la comunidad de artesanos del país, tradiciones costarricenses, la difusión del cine, el teatro, la música, la danza internacional, entre otros.

La extensión docente de la Universidad de Costa Rica representa la vinculación por excelencia de la Universidad con la sociedad. Es en esta modalidad de interacción en que la Universidad tiene la oportunidad de brindar a la sociedad costarricense la colaboración en formación y asesoría que responde a las necesidades de actualización, aprendizaje y desarrollo de estrategias para contribuir con el mejoramiento de la calidad de vida de la población. Se ofrece en diferentes formatos cuya distribución se muestra a continuación: 


\section{Gráfico 4. Distribución de proyectos de extensión docente de acuerdo a los formatos establecidos, 2011. Universidad de Costa Rica.}

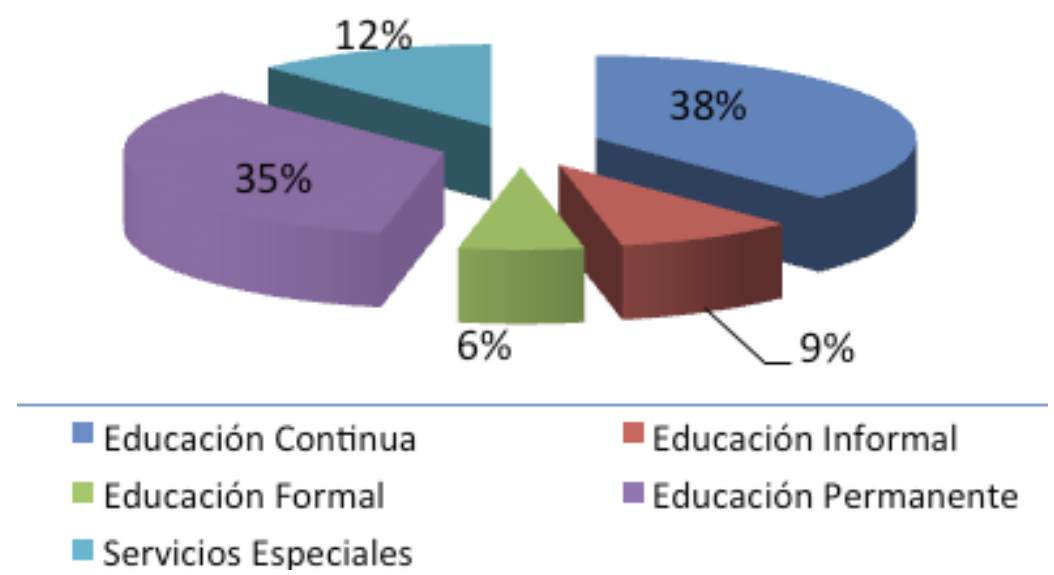

Fuente: Informe de la Rectora, 2010.

Puede observarse que la mayoría de proyectos se ubica en la modalidad de educación continua, modalidad dirigida directamente al mejoramiento de la capacidad para el empleo hacia la población laboral del país. Le siguen los proyectos de educación permanente a los que acceden personas de todas las edades en busca de oportunidades para el mejoramiento personal. La Universidad se involucra en brindar servicios especiales y educación informal a poblaciones específicas como se trata de los Centros Infantiles Laboratorio, el Programa Integral del Adulto Mayor, el Proyecto de Inclusión de Personas con Discapacidad Intelectual a la Educación Superior, entre otros. Como educación formal se ofrecen cursos que llevan a diplomados, aunque no es una práctica muy difundida en la Universidad.

De la anterior información puede concluirse que el desarrollo de la acción social universitaria no se centra exclusivamente en la atención de poblaciones vulnerables, sino en general a todo grupo social que requiera del apoyo universitario como principio de inclusión. No obstante la vulnerabilidad es atendida con una perspectiva de transversalidad de manera que todo proyecto de extensión toma en consideración las necesidades particulares de personas, grupos o poblaciones para brindar el apoyo universitario de acuerdo con estas condiciones. En este caso se tienen experiencias relacionadas con temas de pobreza, de culturas, situaciones relacionadas con violencia de género, apoyo desde diversas disciplinas del área psicosocial como la experiencia de atención ante los desastres, entre otros.

Las diferentes acciones del área de extensión desempeñan un papel de doble vía en el cumplimiento de los principios establecidos en el Estatuto Orgánico de la Universidad de Costa Rica. Por un lado estas acciones permiten a la Universidad brindar apoyo social mediante la transferencia de conocimiento y el trabajo sistemático de la población estudiantil y del profesorado para el mejoramiento comunal. Por otro lado, estas mismas acciones le permiten diagnosticar las necesidades sociales para que este apoyo sea pertinente, es decir, para que se promuevan las transformaciones necesarias para el desarrollo nacional. El elemento básico 
de este mecanismo de doble vía es la promoción de la inclusión social. Se destacan intereses particulares de la institución como lo es las relaciones intergeneracionales, la accesibilidad, cohesión y el fomento de la igualdad de derechos.

\section{Dimensión de evaluación}

La Oficina de Planificación Universitaria ha construido un sistema para la evaluación institucional con 109 indicadores de eficiencia y efectividad para calificar los Planes Anuales Operativos. Estos indicadores, que responden a las diferentes acciones que desarrolla la Universidad y sus diversas áreas sustantivas, toman en consideración aspectos medibles relacionados con Docencia, Investigación, Acción Social, Vida Estudiantil y la Gestión Administrativa. Anualmente se elabora y publica el panorama cuantitativo de la Universidad el cual es utilizado para la evaluación de la gestión y la definición de los planes subsiguientes. Este instrumento ha sido de gran utilidad para la negociación del presupuesto universitario con el gobierno.

Para la evaluación docente, dos diferentes mecanismos son aplicados, uno a nivel institucional a cargo del CEA y otro propio de cada Unidad Académica con la asesoría igualmente de ese centro. El primero se concentra en la evaluación del desempeño docentecurso para el ascenso en Régimen Académico y el segundo se realiza por iniciativa de la instancia que dirige un plan de estudios. Los resultados de este último tipo de evaluación contribuyen al mejoramiento docente del profesorado y por lo tanto de la calidad de la formación profesional, sin embargo como es norma universitaria, las acciones correctivas necesarias para la resolución de situaciones inadecuadas queda en manos de las autoridades de las Unidades Académicas y no existe un registro sistemático en las instancias de gestión central de la Universidad en este sentido.

En Costa Rica existe el Sistema Nacional de Acreditación de la Educación Superior y varias de las carreras de la Universidad de Costa Rica ya han sido acreditadas y otras se encuentran en proceso de evaluación. Los indicadores propios de este sistema están referidos a las siguientes dimensiones: relación con el contexto, recursos, proceso educativo y resultados. Otra experiencia más de evaluación de la calidad académica es la creada por el propio CEA, con el fin de brindar una certificación de calidad a las carreras, con una validez a lo interno de la institución.

El tema de la evaluación en la Universidad cumple con dos propósitos. El primero se relaciona con la rendición de cuentas ante la sociedad a partir del principio de calidad académica y el segundo con la toma de decisiones para el mejoramiento de la gestión académica y administrativa. El sistema de indicadores no solo permite dar a conocer el desempeño universitario, sino que también se revierte en la planificación anual. La evaluación docente igualmente tiene un propósito de mejoramiento que incide también en el desarrollo profesional del personal académico y en la cara visible de la Universidad que constituye la calificación de sus profesores y profesoras.

Es importante mencionar que a lo interno de la comunidad universitaria se ha generado una 
importante discusión acerca de los procesos de evaluación institucional. ¿Son estos una iniciativa propia de la institución en su propio beneficio?¿Es una imposición del mercado? ¿Es que la Universidad ha perdido su prestigio y hegemonía en cuanto a la producción de conocimiento y la formación de profesionales para el desarrollo de la sociedad?

\section{Conclusiones}

A partir de lo expuesto anteriormente se concluye que:

La Universidad de Costa Rica cuenta con la normativa necesaria y suficiente para la promoción de espacios educativos de equidad y cohesión social en consecuencia con los principios de justicia e igualdad que orientan el desarrollo de la nación. No obstante existen algunas condiciones de tipo psicosocial como la identidad de género, la violencia doméstica, los grupos de inmigrantes, el abuso sexual, entre otros ya mencionados, que ameritan de una atención particular y que no están consideradas de manera específica en las normas universitarias, sin embargo han sido poco a poco asumidas por medio de programas y proyectos que se sustentan en los mismos principios humanistas que caracterizan la Universidad y favorecen la promoción del desarrollo del estudiantado en particular y en general de la comunidad educativa. Sin embargo no se puede dar fe de que los principios de esos programas y proyecto estén debidamente introyectados en la cultura institucional, de manera que se pueda evidenciar que en la práctica se asuman por la totalidad de la comunidad universitaria.

La institucionalidad de la Universidad de Costa Rica es fuerte y comprometida con el bienestar de su estudiantado a partir de la legislación nacional y su propia legislación, su estructura orgánica está consolidada de manera que los vínculos jerárquicos muestran una lógica burocrática bastante saludable y la valoración de su pertinencia se sustenta en principios inclusivos y no necesariamente en la sectorialización de las situaciones sociales y culturales que caracterizan a la población estudiantil. Desde la perspectiva de otras tendencias internacionales relacionadas con el tema tratado en este estudio, esto último puede ser considerado como debilidad por no hacer explícitos sus esfuerzos hacia grupos vulnerables, más allá de aquellos en condiciones socioeconómicas precarias, sin embargo la institución aún no ha sentido la necesidad de hacerlo.

La Universidad de Costa Rica ha desarrollado políticas y estrategias para la admisión, la permanencia y la graduación estudiantil dirigidas a todo el estudiantado de acuerdo con sus condiciones generales y específicas. No obstante aún no ha logrado contrarrestar la realidad social del país de manera que todavía persisten desigualdades sobre todo en el acceso a la institución por parte de las y los jóvenes que egresan de la educación media.

La Universidad de Costa Rica ofrece un sistema de méritos al profesorado basado en criterios académicos exclusivamente, el cual permite su ascenso en régimen y por lo tanto el mejoramiento de sus condiciones de contratación. Sin embargo la realidad demuestra que aún prevalece un sesgo de género en beneficio de los profesores, situación que se repite con el profesorado en condición de interinazgo. 
La Universidad de Costa Rica es una institución comprometida con el conocimiento universal que brinda una amplia oferta de formación a su estudiantado. En los últimos años se ha ido aumentando la oferta de carreras, algunas de ellas con perfil interdisciplinario y principalmente en las Sedes Regionales de la institución. Esta condición aporta opciones de formación universitaria a aquellas poblaciones de zonas alejadas que históricamente han tenido menos posibilidades de acceder a la educación. Los planes de estudio se fundamentan en principios propios de la equidad y la cohesión social, no obstante no es posible asegurar que estos se cumplan satisfactoriamente en todas las carreras. En cuanto al desarrollo académico del profesorado persiste aún también un sesgo importante hacia la promoción más de los profesores que de las profesoras aunque las acciones de formación se encuentran abiertas para todo el personal académico.

La Universidad de Costa Rica desarrolla investigación en todas las áreas del conocimiento que integran su quehacer académico. Las políticas en este campo son amplias y generales, lo que permite a cada Unidad Académica y de Investigación determinar sus propias orientaciones en concordancia con las necesidades de desarrollo académico. No obstante nuevamente se muestra un sesgo de género importante al haber más profesores dedicados a la investigación que profesoras, aunque la institución tiene más profesoras que profesores.

Es importante indicar que dentro de la investigación que se realiza se retoman temas que permiten generar conocimiento en relación con el tema que nos ocupa y que facilita la toma de decisiones al respecto.

La Acción Social en la Universidad de Costa Rica se orienta hacia la atención de las necesidades de la sociedad costarricense en general con una visión inclusiva. Si bien sus acciones se dirigen a poblaciones con alta vulnerabilidad social, su compromiso es abierto hacia toda la población en sus diversos ámbitos de desarrollo, entre ellos: el económico, el comunitario, el psicosocial, el educativo, el tecnológico. Su trabajo privilegia a aquellas personas en condiciones que pueden devenir en exclusión social, como la pobreza, la condición de género, la violencia, entre otros con la participación de los diferentes sectores, para contribuir de esta manera en la búsqueda de soluciones en pro de una sociedad más justa.

La Universidad de Costa Rica se ha abierto a la posibilidad de ser sometida al escrutinio de la comunidad nacional para lo cual ha creado sistemas de evaluación basados en el principio de transparencia. Además cada día es más evidente la necesidad de valorar a lo interno la calidad de la acción académica que desarrolla. Surge una preocupación en la comunidad universitaria por el origen de estas respuestas universitarias pues podría estarse dando respuesta a imposiciones de sectores que no son a las que legítimamente debe responder la institución.

Como se puede observar en relación con la promoción de la equidad y la cohesión social, la Universidad de Costa Rica se caracteriza porque a partir de su nacimiento logra desarrollar desde su misma filosofía institucional acciones que la favorecen, destacándose en los últimos años las creación de normativa, programas y proyectos para la atención de poblaciones específicas y atender de esta manera las demandas sociales en este sentido (género, necesidades educativas, atención a la diversidad), pero siempre desde una perspectiva de inclusividad más que de medidas compensatorias. El reto es lograr trasladar esta responsabilidad a toda la comunidad educativa, de manera que se trascienda la normativa y las instancias que por su naturaleza están mayormente vinculadas. 


\section{REFERENCIAS BIBLIOGRÁFICAS}

Asamblea Legislativa de Costa Rica (1940). Ley Orgánica de la Universidad de Costa Rica. San José, Costa Rica. Recuperado de: www.cu.ucr.ac.cr/normativ/ley_de_creacion_ucr.pdf

Barrantes, R. (1999). Investigación. Un camino hacia el conocimiento. Un enfoque cuantitativo y cualitativo. San José, Costa Rica: EUNED.

Benadusi. (2001). Equity and education: a critical review of sociological research and thought, en W. Hutmacher, D. Cochrane y N. Bottani (Eds.), In Pursuit of Equity in Education (Dordrecht, Kluwer Academic Publishers).

Colombia aprende. La red del conocimiento. (s.f.). ¿Por qué la pertinencia educativa? Recuperado de: http://www.colombiaaprende.edu.co/html/home/1592/article-199408.html

Consejo Universitario. (s.f.). Políticas Universitarias. Recuperado de: http://www.cu.ucr.ac.cr/politicas. php?accion $=$ mostrar\&tipo $=p$

De Barbieri, T. (1992). Sobre la categoría de género. Una introducción teórico-metodológica. Revista Interamericana de Sociología 2(2-3). pp. 147-178.

Gewirtz, S. (2004). Equity in education: what counts as success? En L. Moreno Herrera y G. Francia (Eds.), Educational Policies - Implications for equity, equality and equivalence, (pp.) Reports from the Department of Education. Örebro University, 2004: 1.

Gaceta Oficial. (2008). Reglamento de régimen académico y servicio docente. Recuperado de: http:// cu.ucr.ac.cr/normativ/regimen_academico_docente.pdf

Gaceta Universitaria 01-2001 (2001). Reglamento de régimen académico estudiantil Recuperado de: http://www.cu.ucr.ac.cr/normativ/regimen_academico_estudiantil.pdf

Gaceta Universitaria 01-2003 (2003). Reglamento del proceso de admisión mediante prueba de aptitud académica. Recuperado de: http://www.cu.ucr.ac.cr/normativ/admision_por_paa.pdf

Gutiérrez, J. (1994). Métodos y técnicas cualitativas de investigación en Ciencias Sociales. Madrid: Síntesis.

Hutmacher W., Cochrane, D. y Bottani, N. (Eds.). (2001). In Pursuit of Equity in Education. Dordrecht: Kluwer Academic Publishers.

Martín, J. (2008). Participación de la sociedad civil y cohesión social. Unión Europea: Fundación Internacional y para Iberoamérica de Administración y Políticas Públicas (FIIAPP).

Oficina de Asuntos Internacionales. (s.f.) Focus Areas. Recuperado de: http://www.oaice.ucr.ac.cr/es.html

Organización Mundial de la Salud (s.f.). Temas de Salud. Recuperado de: http://www.who.int/topics/ gender/es/

Ortí, A. (1994). La confrontación de modelos y niveles epistemológicos en la génesis e historia de la investigación social. En J. Delgado, y J. Gutiérrez: Métodos y técnicas cualitativas de investigación en Ciencias Sociales, (pp. 87-91) Madrid: Síntesis. 
Pérez, K. (2000). Diccionario de Acción Humanitaria y Cooperación al Desarrollo. Bilbao: Hegoa e Icaria. Recuperado de: http://dicc.hegoa.efaber.net/

Portal de la Investigación. (s.f.). Presentación. Recuperado de: http://www.vinv.ucr.ac.cr/index. php?Itemid=28\&id=12\&option=com_content\&view=article

Programa Estado de la Nación en Desarrollo Humano Sostenible. (1994). Primer Informe del Estado de la Nación en Desarrollo Humano Sostenible. San José, Costa Rica: Autor.

Programa Estado de la Nación en Desarrollo Humano Sostenible. (2010). Decimosexto Informe del Estado de la Nación en Desarrollo Humano Sostenible. San José, Costa Rica: Autor.

Programa Estado de la Nación en Desarrollo Humano Sostenible. (2011). Tercer Informe Estado de la Educación. San José: Autor.

Rodríguez, E. (2000). Entre silencios y voces. Género e historia en América Central (1750-1990). San José, Costa Rica: Editorial de la Universidad de Costa Rica: Instituto Nacional de las Mujeres.

RIFED. (s.f.). Acerca de RIFED. Recuperado de: http://www.rifed.ucr.ac.cr/rifed/

Rojas, R. (1991). Guía para investigaciones sociales. México: Plaza y Valdés.

Rubin, G. (1975) The Traffic in Women: Notes on the 'Political Economy' of Sex; en Reiter, R. (comp.), Toward an Anthropology of Women, Monthly Review Press, Nueva York.

Thompson, J. (2000). Acceso a la Justicia y Equidad. Estudio de siete países de América Latina. San José, Costa Rica: IIDH.

Tünnermann Bernheim, Carlos. (1999). Educación Superior de cara al Siglo XXI. San José, Costa Rica: Mirambell.

Universidad de Costa Rica (1974). Estatuto Orgánico de la Universidad de Costa Rica. San José, Costa Rica. Recuperado de: www.cu.ucr.ac.cr/normativ/estatuto_organico.pdf

Universidad de Costa Rica. (1985). Reglamento de Régimen Académico y Servicio Docente. San José, Costa Rica. Recuperado de: www.cu.ucr.ac.cr/normativ/regimen_academico_docente.pdf

Universidad de Costa Rica. (2001). Reglamento Régimen Académico Estudiantil. San José, Costa Rica. Recuperado de: www.cu.ucr.ac.cr/normativ/regimen_academico_estudiantil.pdf

Universidad de Costa Rica. (2008). Políticas de la Universidad de Costa Rica para los años 2010-2014. Recuperado de: www.cu.ucr.ac.cr/normativ/politicas_institucionales_2010-2014.pdf

Universidad de Costa Rica. (2010). VI Informe Anual de Labores de Rectoría 2009-2010. Recuperado de: http://www.ucr.ac.cr/informe-rectoria.html

Universidad de Costa Rica. (2008). Plan de Desarrollo Institucional 2008-2012. Recuperado de: http:// oplau.ucr.ac.cr/phocadownload/plan desarrollo/vinculacion pdi con politicas2010-2014.pdf

Villasante, T. (1994). De los movimientos sociales a las metodologías participativas, en Delgado, J. y Gutiérrez, J.: Métodos y técnicas cualitativas de investigación. En Ciencias Sociales. Madrid: Síntesis. 